PNL- 4026 I-

NUREG/CR-2468 PNL-4026

\title{
State-of-Practice Review of
}

Ultrasonic In-Service Inspection of Class I System Piping in Commercial Nuclear Power Plants

Prepared by C. J. Morris, F. L. Becker

Pacific Northwest Laboratory

Operated by

Battelle Memorial Institute

Prepared for

U.S. Nuclear Regulatory

Commission 


\section{NOTICE}

This report was prepared as an account of work sponsored by an agency of the United States Government. Neither the United States Government nor any agency thereof, or any of their employees, makes any warranty, expressed or implied, or assumes any legal liability of responsibility for any third party's use, or the results of such use, of any information, apparatus, product or process disclosed in this report, or represents that its use by such third party would not infringe privately owned rights.

\section{Availability of Reference Materials Cited in NRC Publications}

Most documents cited in NRC publications will be available from one of the following sources:

1. The NRC Public Document Room, 1717 H Street, N.W. Washington, DC 20555

2. The NRC/GPO Sales Program, U.S. Nuclear Regulatory Commission, Washington, DC 20555

3. The National Technical Information Service, Springfield, VA 22161

Although the listing that foliows represents the majority of documents cited in NRC publications, it is not intended to be exhaustive.

Referenced documents available for inspection and copying for a fee from the NRC Public Document Room include NRC correspondence and internal NRC memoranda; NAC Office of Inspection and Enforcement bulletins, circulars, information notices, inspection and investigation notices; Licensee Event Reports; vendor reports and correspondence; Commission papers; and applicant and licensee documents and correspondence.

The following documents in the NUREG series are available for purchase from the NRC/GPO Sales Program: formal NRC staff and contractor reports, NRC-sponsored conference proceedings, and NRC booklets and brochures. Also available are Regulatory Guides, NRC regulations in the Code of Federal Regulations, and Nuclear Regulatory Commission /ssuances.

Documents available from the National Technical Information Service include NUREG series reports and technical reports prepared by other federal agencies and reports prepared by the Atomic Energy Commission, forerunner agency to the Nuclear Regulatory Commission.

Documents available from public and special technical libraries include all open literature items, such as books, journal and periodical articles, and transactions. Federal Register notices, federal and state legislation, and congressional reports can usually be obtained from these libraries.

Documents such as theses, dissertations, foreign reports and translations, and non-NRC conference proceedings are available for purchase from the organization sponsoring the publication cited.

Single copies of NRC draft reports are available free upon written request to the Division of Tech. nical Information and Document Control, U.S. Nuclear Regulatory Commission, Washington, DC 20555.

Copies of industry codes and standards used in a substantive manner in the NRC regulatory process are maintained at the NRC Library, 7920 Norfolk Avenue, Bethesda, Maryland, and are available there for reference use by the public. Codes and standards are usually copyrighted and may be purchased from the originating organization or, if they are American National Standards, from the American National Standards Institute, 1430 Broadway, New York, NY 10018.

GPO Printed copy price: $\$ 5.00$ 
NUREG/CR-2468

PNL-4026

R5

\section{State-of-Practice Review of Ultrasonic In-Service Inspection of Class I System Piping in Commercial Nuclear Power Plants}

Manuscript Completed: June 1982

Date Published: August 1982

Prepared by

C. J. Morris, F. L. Becker

Pacific Northwest Laboratory

Richland, WA 99352

Prepared for

Division of Engineering Technology

Office of Nuclear Regulatory Research

U.S. Nuclear Regulatory Commission

Washington, D.C. 20555

NRC FIN B2289 


\section{ABSTRACT}

The Pacific Northwest Laboratory conducted a survey to determine the state of practice of uitrasonic in-service inspection of primary system piping in light water reactors. Personnel at four utilities, five inspection organizations, and three domestic reactor manufacturers were interviewed. The intention of the study was to provide a better understanding of the actual practices employed in in-service inspection of primary system piping and of the difficulties encountered.

Among the principal findings of this state-of-practice review are:

1. Test procedures are very similar among the different organizations and are in general designed to meet only minimum requirements of Section XI of the ASME Boiler and Pressure Vessel Code. Supplemental tests (after a defect indication has been located) are substantially different.

2. Selection of ultrasonic search units is highly variable.

3. Confidence in the ability to detect defects was highest for ferritic piping and lowest for cast stainless steel.

4. Recording of geometrical indications during baseline preservice inspection or in-service inspection is not consistent and, therefore, of limited value. 



\section{CONTENTS}

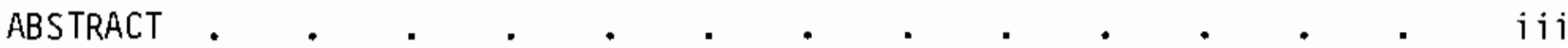

GLOSSARY OF ABBREVIATED TERMS • . . . . . . . . . . . . . . . . ix

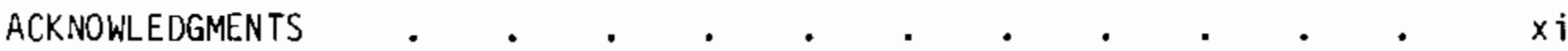

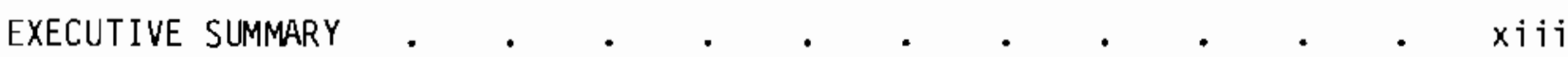

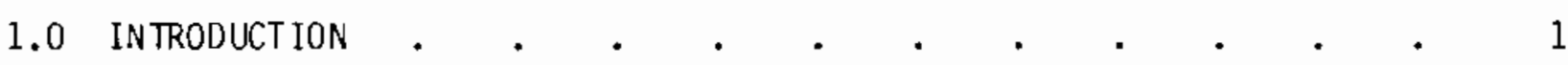

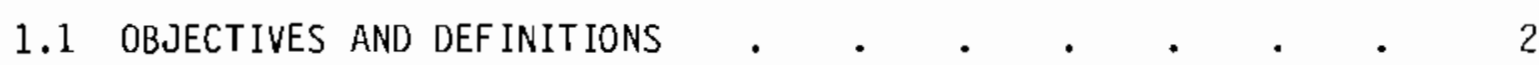

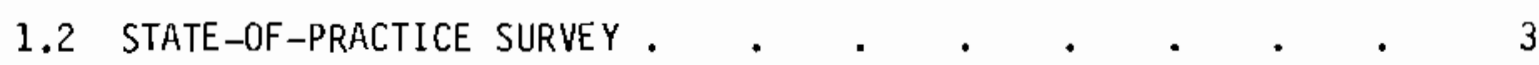

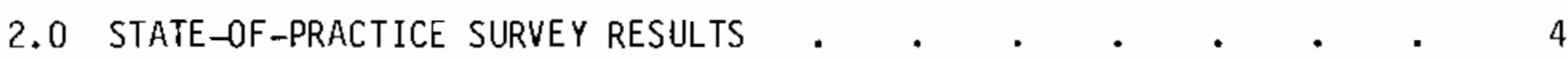

\begin{tabular}{l}
2.1 UTILITY, INSPECTION ORGANIZATION, AND REACTOR \\
VENDOR EXPERIENCE \\
\hline
\end{tabular}

2.2 SELECTION AND PERFORMANCE VERIFICATION OF TRANSDUCERS 6

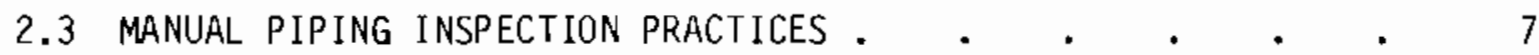

2.4 INSPECTION PRACTICES FOR FERRITIC AND STAINLESS STEEL PIPE • 8

2.5 EXPERIENCE WITH CENTRIFUGALLY CAST STAINLESS STEEL PIPE $\quad 9$

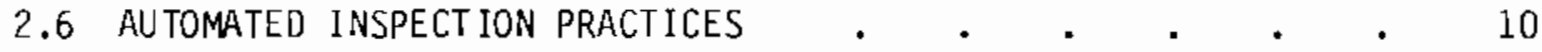

2.7 PIPE OUTER DIAMETER GEOMETRY CONDITIONS • $\quad$ • $\quad$ • 12

2.8 PIPE INNER DIAMETER GEOMETRY CONDITIONS • • • • • • • 14

2.9 CALIBRATION, INSPECTION, AND FLAW EVALUATION . . . . 17

2.10 EXPERIENEE WITH DISSIMILAR METAL WELDS • • • • • • 20

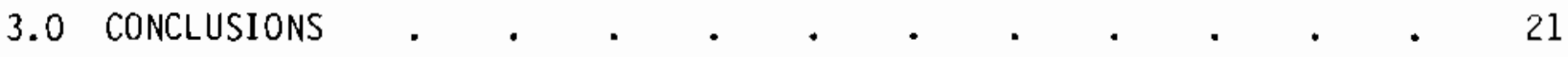

4.0 RECENT EXPERIENCES . . . . . . . . . . . . . . . . . . . . 23

4.1 IGSCC DETECTION

4.2 CENTRIFUGALLY CAST STAINLESS STEEL • • • • • • • • • 25

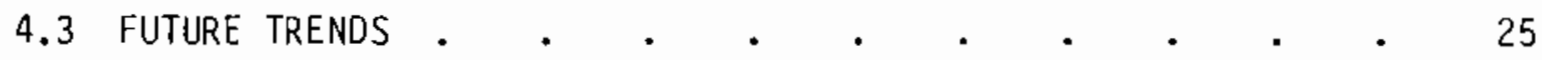




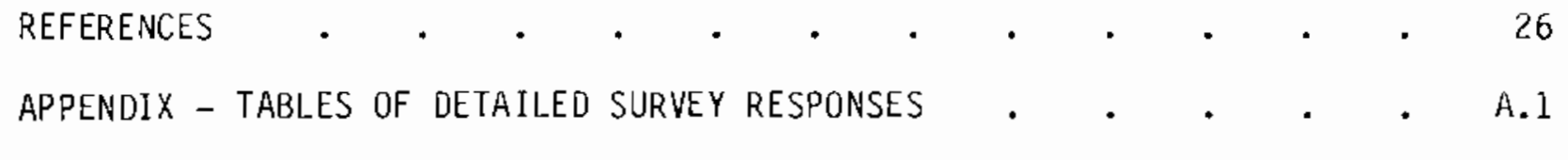




\section{FIGURES}

1 Cross Section of a Typical Welded Pipe Joint . . . . . 3

2 Pipe Cross Section of Centrifugally Cast Stainless Stee? . . 11

3 Outer Diameter Geometry Conditions . . . . . . . . 13

$4 \quad 1 / 2 \vee$ and Full V Path Ultransonic Weld Examination $\quad . \quad$. 14

5 Pipe Counterbore Geometry Conditions . . . . . . . . 16

6 Pipe Innter Diameter Suck-Up and Drop-Through Conditions. . . 17

$73 / 2$ Examination with the Beam Incident on the Conical Section of the Counterbore (mode conversion of shear to longitudinal wave at conical section of counterbore) . $. \quad . \quad . \quad . \quad . \quad 18$ 



\section{GLOSSARY OF ABBREVIATED TERMS}

\begin{tabular}{|c|c|}
\hline ASME Code & $\begin{array}{l}\text { Boiler and Pressure Vessel Code published by the American } \\
\text { Society of Mechanical Engineers }\end{array}$ \\
\hline ASNT & American Society for Nondestructive Testing \\
\hline ASTM & American Society for Testing and Materials \\
\hline BWR & boiling water reactor \\
\hline CB & counterbore \\
\hline $\operatorname{ccss}$ & centrifugally cast stainless steel \\
\hline DAC & distance amplitude correction \\
\hline EPRI & Electric Power Research Institute \\
\hline ID & inner diameter \\
\hline IGSCC & intergranular stress corrosion cracking \\
\hline IIW & International Institute of Welding \\
\hline ISI & inservice inspection \\
\hline KB & Krautkramer Branson \\
\hline L-wave & Tongitudinal wave \\
\hline LWR & light water reactor \\
\hline MT & magnetic particle test \\
\hline NA & not applicable \\
\hline NDE & nondestructive evaluation \\
\hline OD & outer diameter \\
\hline PNL & Pacific Northwest Laboratory \\
\hline PSI & preservice inspection \\
\hline PT & dye penetrant testing \\
\hline PVRC & Pressure Vessel Research Committee \\
\hline PWR & pressurized water reactor \\
\hline
\end{tabular}




$\begin{array}{ll}\text { RF } & \text { radio frequency } \\ \text { rms } & \text { root mean square } \\ \text { RT } & \text { radiographic testing } \\ \text { SDH } & \text { side drilled hole } \\ \text { SS } & \text { stainless steel } \\ \text { T } & \text { pipe wall thickness } \\ \text { UT } & \text { ultrasonic testing } \\ \text { V } & \text { full V metal path }\end{array}$




\section{ACKNOWLEDGMENTS}

The authors would like to acknowledge the assistance of Eugene Reinhart of Reinhart and Associates, Austin, Texas, for his assistance in compiling this aata. The authors would also like to thank utility, ISI vendor, and NSSS personnel for their cooperation in this study. The authors would also like to thank Steve Matsumoto for his assistance in editing and preparation of this manuscript. 



\section{EXECUTIVE SUMMARY}

The Pacific Northwest Laboratory conducted a survey to determine the state of practice of ultrasonic in-service inspection of primiary system piping in light water reactors. This state-of-practice review was conducted to define the actual procedures and practices applied in the field. Personnel at four utilities, five inspection organizations, and three domestic reactor manufacturers were interviewed.

- The principal findings of this review are:

1. Test procedures are very similar among the different organizations and are in general designed to meet only minimum requirements of Section XI of the ASME Boiler and Pressure Vessel Code. Supplemental tests (after a defect indication has been located) are substantially different.

2. Selection of ultrasonic search units is highly variable.

3. Onjy one organization measures and periodically verifies the operating characteristics of their search units.

4. Confidence in the ability to detect defects was highest for ferritic piping and lowest for cast stainless steel.

5. Recording of geometrical indications during baseline preservice inspection or in-service inspection is not consistent and, therefore, of 1 imited value.

6. Nominal and worst-case counterbore conditions described by the inspectors provide an insight into the inspection difficulties produced by this condition.

This document is intended to provide the reader with a better understanding of the actual practices employed in in-service inspection of primary system piping as well as the difficulties encountered. Areas of concern listed in this document are currently under investigation to determine their impact on inspection reliability. Results of these investigations will be reported separately. 

STATE-OF-PRACTICE REVIEW OF ULTRASONIC IN-SERVICE INSPECTION OF CLASS I SYSTEM PIPING IN COMMERCIAL NUCLEAR POWER PLANTS

\subsection{INTRODUCTION}

In-service inspection of the primary piping systems in commercial light water reactors is performed to meet the requirements of Section XI of the American Society of Mechanical Engineers (ASME) Boiler and Pressure Vessel Code (hereafter referred to as Code) and Appendix III of Section Xi (ASME 1977a). Periodic inspections of a sampling of pipe joints are made 1) to assure that cracks are not growing while pipes are in service and 2) to identify generic defects that may be present in the remainder of the system or in similar systems.

The adequacy of ASME Section XI requirements for assuring continued operating safety has not been conclusively established. Safety analyses therefore give little credence to the ability of in-service inspection (ISI) to detect defects that may result in pipe failure. The U.S. Nuclear Regulatory Commission (NRC) is sponsoring several programs directed at establishing the credibility of ISI and identifying the requirements necessary to assure light water reactor (LWR) operating safety. The Pacific Northwest Laboratory (PNL) was selected by the NRC to conduct a five-year program, "Integration of Nondestructive Evaluation Reliability and Fracture Mechanics," (Becker 1981).

Early in the program it was recognized that there was a lack of information regarding the procedures practiced by organizations performing ISI of primary system piping at commercial LWRs. Uncertainty existed as to the specific techniques, procedures, equipment, transducers, methods of signal evaluation, etc. in use for ISI at nuclear power plants. Research staff at PNL feit that current practices were highly variable and that the procedures should be documented for reference and for guidance in future research. This report documents one task of the program: a state-of-practice review of the available technology, procedures, and practices employed for ASME Code Section XI inspection of Class I system piping and components at comnercial nuclear power plants. 
This state-of-practice review was accomplished by literature review, personal interviews, and a survey of personnel at several utilities, private inspection organizations, and domestic reactor manufacturers. The objectives of the review (and definitions of tems important to the review) are discussed in Section 1.1 .

The personal interviews and survey, which were the major part of the state-of-practice review, are discussed in Section 1.2.

The results of the survey are presented in Section 2 with subsequent conclusions in Section 3. An appendix supplies details of responses obtained in the survey.

\subsection{OBJECTIVES AND DEF INITIONS}

The first objective of the review was to define current ultrasonic inspection technology as practiced in the field, including procedures and practices used for the required ASME Code volumetric examination of Class I piping and components in commercial LWRS. Section XI of the Code defines the in-service inspection requirements for nuclear power plant components. Specific to this study, Subsection IWB-2500 of Section XI (Categories B-F and B-J) defines those areas subject to examinations and the extent and frequency of examinations for Class I pressure-retaining welds. Subsection IWB-2500 requires volumetric examination of these important Class I pipe welds with ultrasonic inspection being the preferred method of examination. Figure 1 shows a cross section of a typical welded pipe joint.

A second objective was to define a combination of test procedure and equipment that is most typical of field practice and that could be used as a basis for determining the capability and reliability of current ultrasonic inspection practices for detecting and sizing flaws in Class I piping.

The state of practice is the technology which is commonly applied in the field. The state of the art is (by our definition) the technology that has been proven in use and is generally accepted but not necessarily by codewriting organizations. A third category is advanced technology, techniques that are under laboratory study but which have not been demonstrated in the field. 


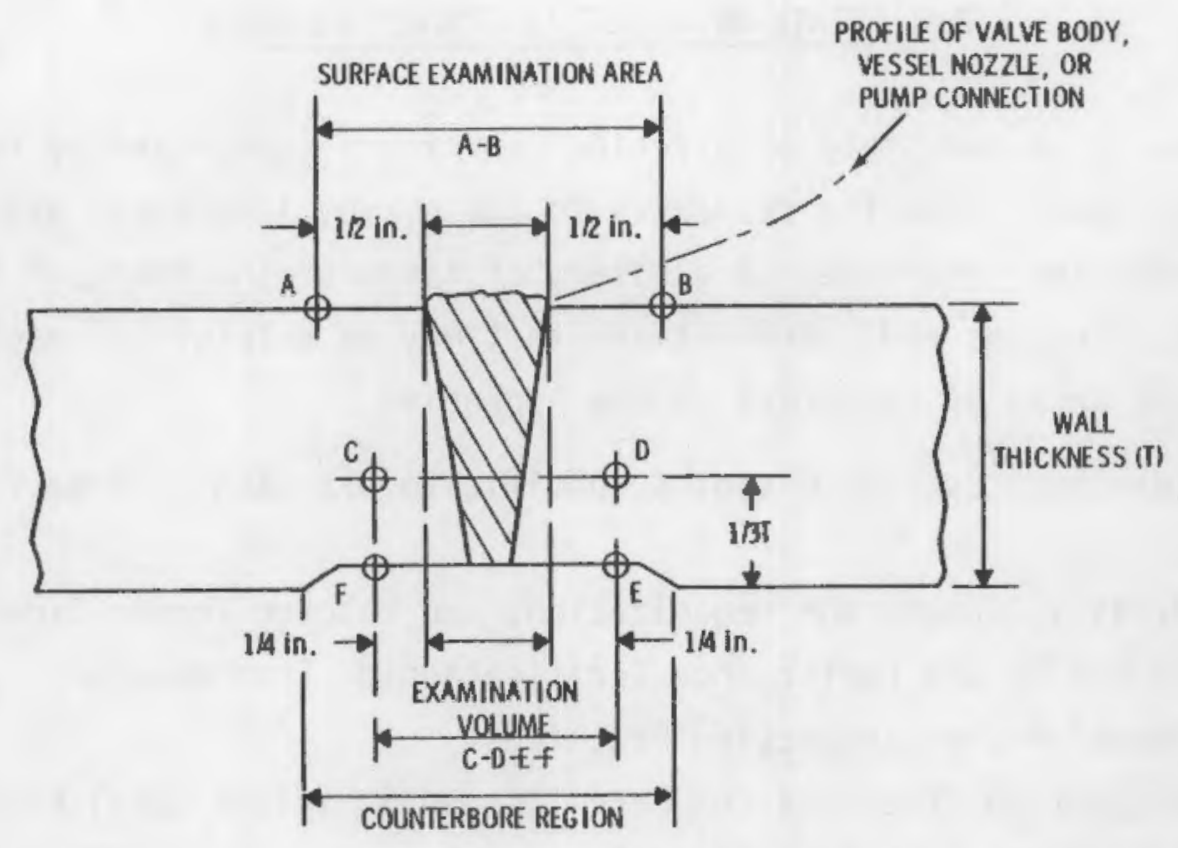

FIGURE 1. Cross Section of a Typical Welded Pipe Joint

\subsection{STATE-OF-PRACTICE SURVEY}

This report discusses the information received as a result of personal interviews with four utilities, five private inspection organizations, and three domestic reactor manufacturers. Information furnished to PNL described ultrasonic inspection techniques, test procedures specific to materials examined, equipment and transducers, standards, confidence limits, and problem areas such as pipe counterbore geometry.

Interviews were made with key personnel who were knowledgeable of the ISI field practices of their organization. The individual responses to the survey (as presented in the Appendix) are limited in that they are often the opinions of one or two persons in a large organization. However, efforts were made to assure that these were well-informed opinions: together the interviewed organizations encompass the major portion of domestic ISI experience in ultrasonic inspection of Class I piping in nuclear power plants.

The next section covers the results of the survey. 


\subsection{STATE-OF-PRACTICE SURVEY RESULTS}

The results of the state-of-practice survey are summarized by topic in the following sections. Specific responses to the survey interviews are included in the Appendix for reference. A glossary of terms at the front of this document presents acronyms and abbreviations that may be helpful in reading this summary or the detailed responses in the Appendix.

The interviews covered 10 topics specific to ultrasonic in-service inspection:

2.1 Utility, Inspection Organization, and Reactor Vendor Experience

2.2 Selection and Performance Verification of Transducers

2.3 Manual Piping Inspection Practices

2.4 Inspection Practices for Ferritic and Stainless Steel Pipe

2.5 Experience with Centrifugally Cast Stainless Steel Pipe

2.6 Automated Inspection Practices

2.7 Pipe Outer Diameter Geometry Conditions

2.8 Pipe Inner Diameter Geometry Conditions

2.9 Calibration, Inspection, and Flaw Evaluation

2.10 Experience with Dissimilar Metal Welds.

\subsection{UTILITY, INSPECTION ORGANIZATION, AND REACTOR VENDOR EXPERIENCE}

This topic covered questions about the number of in-service inspections that a company typically performs per year. Utilities were asked as to their degree of participation in the ISI program. Pacific Northwest Laboratory was interested in determining where the majority of inspection experience is being accumulated and to what extent utility personnel actually participate. In addition, PNL was interested in the inspection philosophy of these organizations and possible suggestions for improving in-service programs based on their experience.

Recognizing current inspection problems with intergranular stress corrosion cracking (IGSCC) in the austenitic stainless steels, PNL asked respondents about the number of inspections in which they had participated, looking specifically for IGSCC. Respondents were also asked about their experience and 
confidence in the inspection of centrifugally cast stainless steel (CCSS) welds. The large grain structure characteristic of cCSS creates uncertainty in the inspectability of CCSS welds. Responses to these questions are detailed in Section 2.5, Experience with Centrifugally Cast Stainless Steel Pipe.

To date no in-service cracks have been found in the main loop coolant piping at domestic pressurized-water reactors (PWRs). Private ISI organizations and reactor vendor organizations perform about $95 \%$ of the domestic ISI programs at commercial nuclear power plants, of which there are currently 72 operating units. Utility personnel generally plan and oversee the ISI program with inspections by utilities themselves generally limited to special problem areas. However, the trend at some of the larger nuclear utilities is to increase utility inspection staff, thereby improving in-house inspection capability in addition to having broader versatility to plan, conduct, and execute their in-service inspection, testing, and maintenance programs. One utility estimated that $20 \%$ to $30 \%$ of ISI would be performed by in-house staff.

The survey respondents had different levels of inspection experience with IGSCC. Because of the incidence of IGSCC at certain domestic plants, the experience of utility and inspection personnel at these affected plants appears substantia1. By comparison, one respondent from an inspection organization that participates in 30 to 40 ISI programs yearly stated that, to his knowledge, their people were not involved with any inspections looking specifically for IGSCC. Another respondent indicated that his company had been contracted specifically to look for IGSCC in certain piping systems at four plants; a) though he found no strong evidence of IGSCC, there was uncertainty at two plants concerning ultrasonic indications in the sensitized area of some welds. Respondents' answers also indicated differences in IGSCC test procedures, examination techniques, transducers, data recording levels, training, and standards. These differences are discussed further in Section 2.4, Inspection Practices for Ferritic and Stainless Steel Pipe.

The Electric Power Research Institute and the U.S. Nuclear Regulatory Commission are funding several research programs concerning IGSCC in piping systems. 


\subsection{SELECTION AND PERFORMANCE VERIFICATION OF TRANSDUCERS}

Several studies (Buchanan 1976; ASNT 1977; Serabian and Lawrie 1977; Birks and Lawrie 1978) have shown the dramatic variability in measurement accuracy and repeatability that result when transducers are not properly characterized but randomly selected for use. This topic covered questions concerning the criteria for selecting transducers and the methods used to verify the operation and performance of transducers. Respondents were asked if certain parameters (such as center frequency, radio frequency (RF), waveform, sensitivity, or frequency bandwidth) were routinely measured to verify transducer performance. Respondents were also asked about methods used to periodically check transducer performance. Numerous technical studies now under way under the auspices of the U.S. Naval Research Laboratory, National Bureau of Standards, ASTM, PVRC committees, and other organizations are emphasizing the development of appropriate specifications and testing procedures for the evaluation of ultrasonic system components.

Inspectors select transducers based on inspection experience and the demands of a given test procedure. A typical test procedure states the nominal operating frequency and transducer size range that can be used. For shear wave examination, beam spread and exit point are measured.

In order to verify initial transducer performance, most companies request manufacturer's certification (RF waveform and frequency spectrum) and the results of a standard calibration. Center frequency is generally assumed from manufacturer's certification; two respondents check center frequency themselves, and one respondent checks the beam profile. Others feel that taking a beam profile has little merit.

The industry makes no checks of near-surface resolution. One company checks transducers on an inner-diameter reflector (notch) if they are going to inspect thin-wall pipe. Calibration blocks with side-drilled holes (SDH) are used to calibrate for distance amplitude correction (DAC) and to establish a sensitivity level. Resolution is checked using SDH. Almost half the respondents use International Institute of Welding (IIW) blocks for verification of beam angle and exit point. One respondent uses an IIW design modified to closer tolerances $\left(1^{\circ}\right.$ measurements added). 
Records of transducer certification are of ten kept, and all DAC curves are recorded and documented as required by test procedures. The philosophy of several respondents was that a successful DAC calibration (within a few decibels of typical values for a specific pipe standard) indicates that the transducer is good. Any need for a significant increase in gain to maintain a given DAC curve is often perceived as a sign of transducer problems. Only one respondent indicated the use of periodic (biannual) checks on transducer performance (RF waveform frequency spectrum and distance-versus-amplitude plot).

All respondents estimated that the typical lifetime of an angle-beam transducer is two to three years for inspection organizations. Special units may last up to five years.

\subsection{MANUAL PIPING INSPECTION PRACTICES}

This series of questions was intended to identify the uitrasonic flaw detection instruments used in practice: the make, model, modifications (if any), and reasons for modifications. The use of electronic DAC, external recording devices, requirements on warm-up time, and periodic calibration or measurement requirements not specified by Code were also covered in the survey.

A1though companies use many different instruments for manual piping inspection, the most common is a Sonic Mark I. The Nortec 1310, KrautkramerBranson USIP II, and Branson 301 and 303 instruments are also widely used. These instruments are usually unmodified with no particular requirements other than manufacturer specifications for instrument pulser or receiver bandwidth. Electronic DAC is not used for manual pipe inspection. Only one respondent uses an external recording device (a strip chart) to record all analog data (metal path and amplitude) for each weld inspection.

Standard practice is to completely wrap the instrument in a plastic bag to protect it from contamination. The bag is taped, and the instrumenttransducer system is then calibrated. The most common practice is to recalibrate the instrument before it is removed from the reactor containment area before decontamination. All respondents indicated that wrapping the instrument 
does not alter instrument performance. However, there was concern about instability problems that occur in containment at temperatures of $125^{\circ} \mathrm{F}$ and higher.

Less than half of the respondents apply periodic calibration or measurement requirements more frequently than specified by code.

The requirements for instrument warm-up time vary from no warm-up to thirty minutes for manual systems and one hour for automated systems. Although several companies have no requirements for warm-up time, the instrument is usually on two to five minutes before the operators are ready to begin inspection. Two companies that recommended a specific time for instrument warm-up indicated that their test procedure did not call for it. One respondent observed a three-decibel difference between instrument calibration after warmup and calibration immediately after the instrument is turned on. A few companies noted problems with instrument stability that were related to instrument warm-up time, battery charge, or line voltage fluctuation. One respondent noted that portable instruments are generally sensitive to line voltage and temperature changes. Another respondent found line voltage fluctuations to be a problem when a generator was used for automatic inspection at some sites; he also found that using new batteries for each major inspection alleviates problems that occur with battery-powered units.

\subsection{INSPECTION PRACTICES FOR FERRITIC AND STAINLESS STEEL PIPE}

Questions were intended to identify the specific transducers and any special procedures used for testing and detecting cracks in ferritic steel and austenitic stainless steel (SS) piping. Respondents were asked to indicate what confidence they had in detecting cracks.

The industry uses tranducers of many different sizes with transducer selection dependent on pipe wall thickness--generally the thicker the wall, the larger the transducer. Typically, minimum Code inspection requirements are performed: on ferritic pipe, a $45^{\circ}$ shear wave examination at $2.25 \mathrm{MHz}$. Standard Code procedures are used without exception; no special procedures are used. Inspection confidence for crack detection with ferritic pipe was very high. 
Many respondents use the same transducers for austenitic SS pipe inspection as those used for ferritic pipe inspection: 2.25-MHz, single-element transducers at $45^{\circ}$ shear wave examinations. Several companies use transducers of the same size but with a 1.5-MHz nominal frequency. Special test procedures with more extensive examination techniques are required by some companies.

All respondents have evaluated or have experience in using a dual-element transducer for inspection of austenitic SS pipe. The reported advantages of the dual-element transducer are "less noise," "cleaner recording," and "seems to work well with thin-wall material." Other respondents are considering use of the dual-element units but have no specific plans for using them.

Most companies use the same pipe test standards for IGSCC inspection of austenitic SS pipe as they use for ferritic pipe inspection (i.e., 10\%T notch) per ASME Code Section XI, Appendix III. Two companies use a $5 \%$ T notch standard, and one company uses actual IGSCC pipe samples. Several respondents indicated that it would be most beneficial to make available to inspection personnel the many IGSCC samples that are stored at several sites in the U.S. Several companies concerned with ultrasonic examination of pipe welds for IGSCC have developed written procedures similar to those documented by Serabian and Lawrie (1977).

Confidence in detecting IGSCC in austenitic SS with depths from $10 \%$ to $25 \%$ of wall thickness (T) ranged between $50 \%$ to $85 \%$. One respondent indicated that confidence in detecting cracks at $10 \% \mathrm{~T}$ is "borderline." At $25 \%$ to $50 \% \mathrm{~T}$ inspection confidence averaged about $78 \%$. At greater than $50 \% \mathrm{~T}$, inspection confidence averaged about $95 \%$. These confidence estimates are based on the experience of the individual respondents and have little statistical significance; however, they indicate the relative degree of difficulty associated with detection of flaws in austenitic SS compared to ferritic material.

\subsection{EXPERIENCE WITH CENTRIFUGALLY CAST STAINLESS STEEL PIPE}

Respondents were asked several questions concerning their experience with the inspection of CCSS pipe. Use of specific transducers, procedures, instruments, standards, and test confidence estimates were discussed. 
Respondents estimated that 8 to 10 domestic plants contain primary reactor coolant piping of CCSS. At least half of the respondents indicated some experience with CCSS pipe. The preferred method of examination is with a 1.0- or 1.5-MHz single-element or dual-element transducer using a refracted longitudinal wave incident at $40^{\circ}$ to $45^{\circ}$. Standard field flaw detector instruments are used in conducting the examination. Because of the characteristically large, finger-like grains of this material (see Figure 2), examination of the weld using $45^{\circ}$ refracted shear waves is impractical.

Most of the inspection experience with CCSS seems to be with one inspection organization. This respondent felt confident that one could detect any significant flaws using a $40^{\circ}$ to $45^{\circ}$ refracted longitudinal technique. Other respondents with experience in inspection of this material were more pessimistic about the detection capability and reliability of this ultrasonic inspection technique and showed a wide range of inspection-detection confidence. Some specific comments were: "difficult", "not very confident in test", "fair-good", "pretty good", "can see Code-size reflectors; however, there are many metallurgical reflectors in this cast material."

Current standards are pipe sections with 5\% T Code notches and/or sidedrilled holes. Several respondents indicated the need for better standards.

All respondents agreed that there is a need for additional study on inspection practices for CCSS pipe, and one reactor vendor is conducting a substantial program on the inspection of CCSS pipe.

\subsection{AUTOMATED INSPECTION PRACTICES}

This topic details the industry use of automated ultrasonic inspection systems: frequency of use, estimates of relative efficiency, data recording standards, couplants used, and special requirements.

Most respondents had used automated inspection systems but only to inspect nozzle-to-safe-end and safe-end-to-pipe welds. Respondents indicated that automated inspection accounts for $5 \%$ to $25 \%$ of the inspection program. The respondent who quoted a $25 \%$ use of automated systems indicated that this is only used during the preservice (baseline) inspection program. 


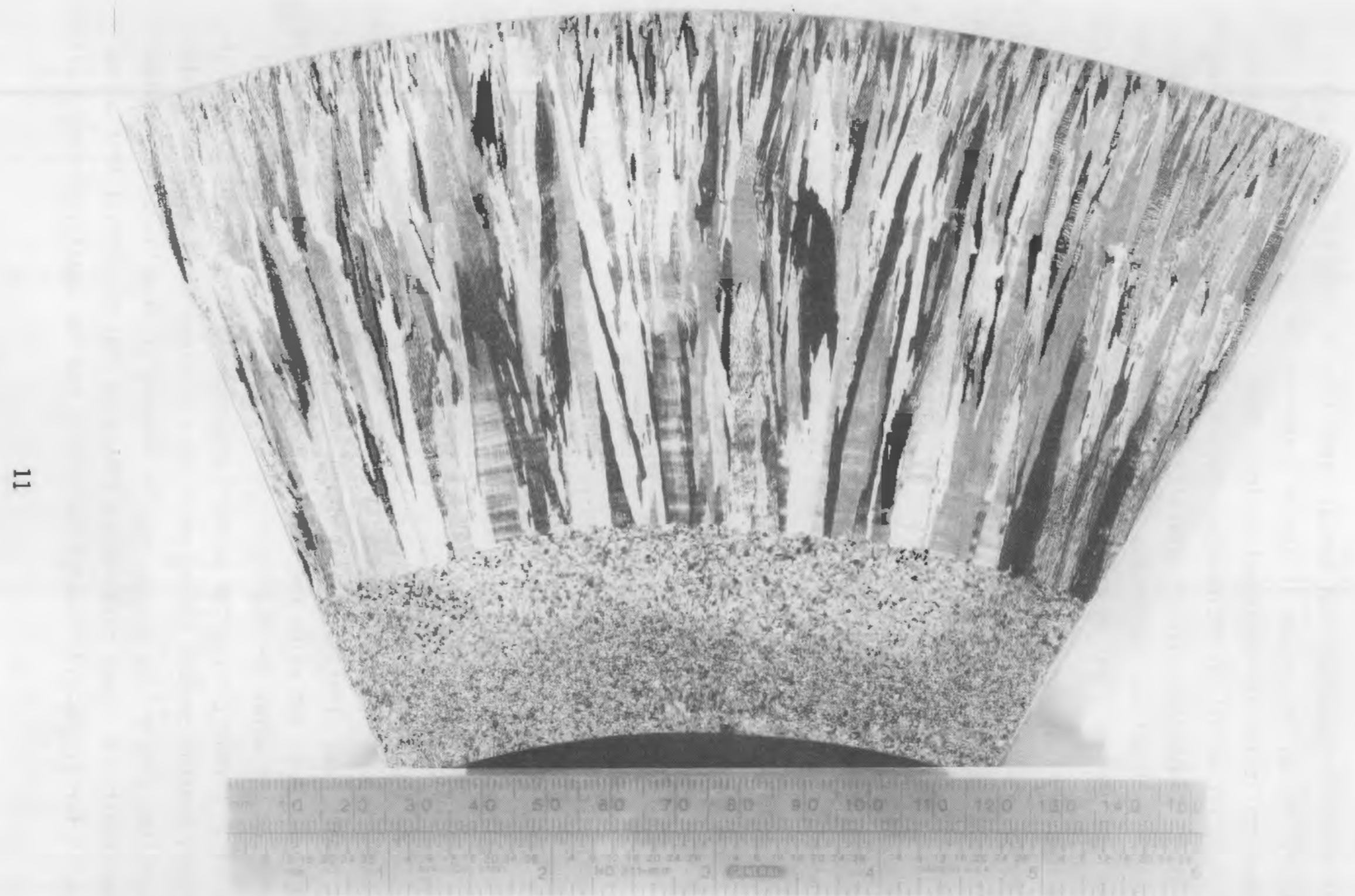

FIGURE 2. Pipe Cross Section of Centrifugally Cast Stainless Steel 
A11 respondents stated that manual inspection is superior to automatic inspection. Manual inspection is always preferred for critical problems. One respondent criticized the equipment design. Automated systems are unproven, require specific access conditions, and seem to break down at the most inappropriate times. Automated systems typically require as much time as manual systems (or more) to set up, calibrate, and conduct an inspection. Automated systems are less versatile but do offer improvements in measurement repeatability.

No industry standard exists for recording automatic inspection data. Strip charts, analog magnetic tape recording, analog-to-digital conversion with magnetic tape recording, and videotapes are current methods of recording ultrasonic data.

Water is the sound couplant for these automated systems. Systems are calibrated statically using pipe standards supplied by the utility, and then placed on the pipe for the dynamic inspection of the welds.

Weld preparation is important when employing automated systems. In practice these systems do require certain access limits. Typical access requirements (e.g., safe-end) are $18 \mathrm{in}$. on either side of the weld. Weld crown height should be flush or have a smooth taper.

\subsection{PIPE OUTER DIAMETER GEOMETRY CONDITIONS}

The survey discussion of pipe outer diameter (OD) geometry included information on single-side access, weld crown height, diametrical shrink, surface finish, overground conditions, and pipe-to-component 00 conditions (see Figure 3).

Respondents estimated that typically $20 \%$ of the welds for Class I reactor coolant piping have single-side inspection access. However, one company replied that $90 \%$ of the welds for their PWR units have single-side access and $60 \%$ to $70 \%$ of the welds for their boiling water reactors (BWRs) have singleside access. Further, a reactor vendor spokesman stated that $90 \%$ to $100 \%$ of the primary reactor coolant system welds have single-side access. Respondents indicated that single-side access results because of pipe-to-valve and pipeto-elbow conditions. Most respondents indicated that no special test procedures exist for single-side inspection access; one can usually perform a $1 / 2 \mathrm{~V}$ 


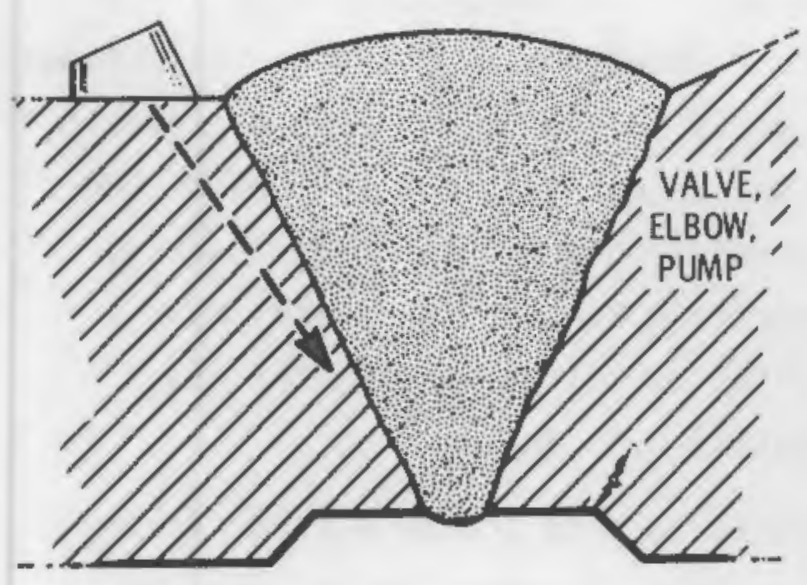

a) Single-Side Access

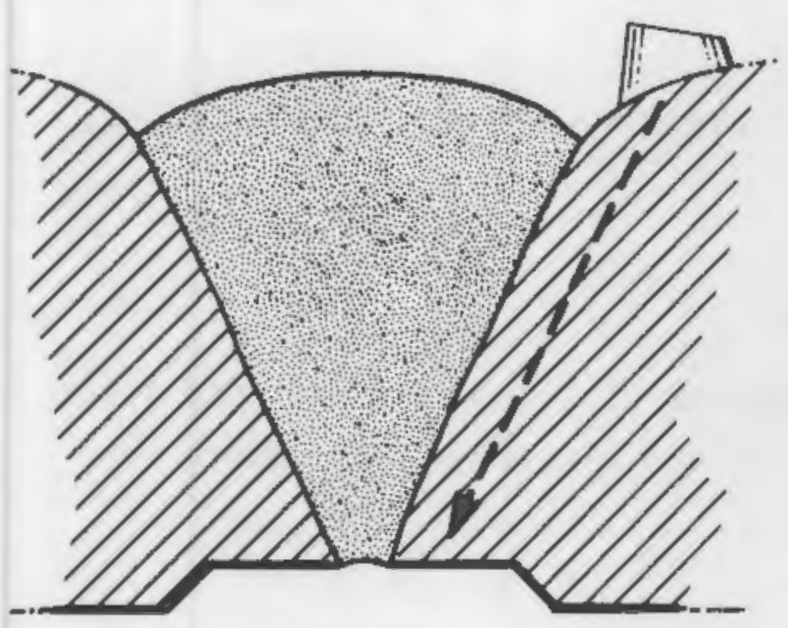

c) Diametral Shrinkage

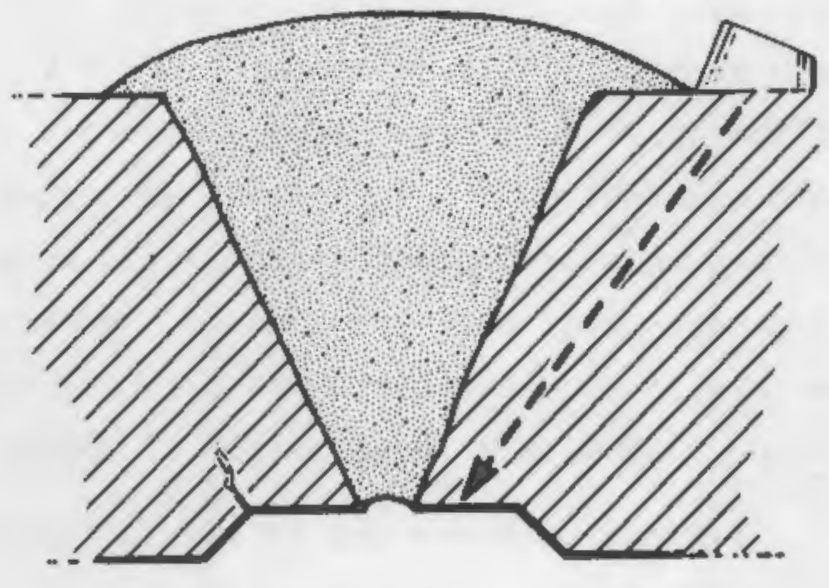

b) Excessive Crown

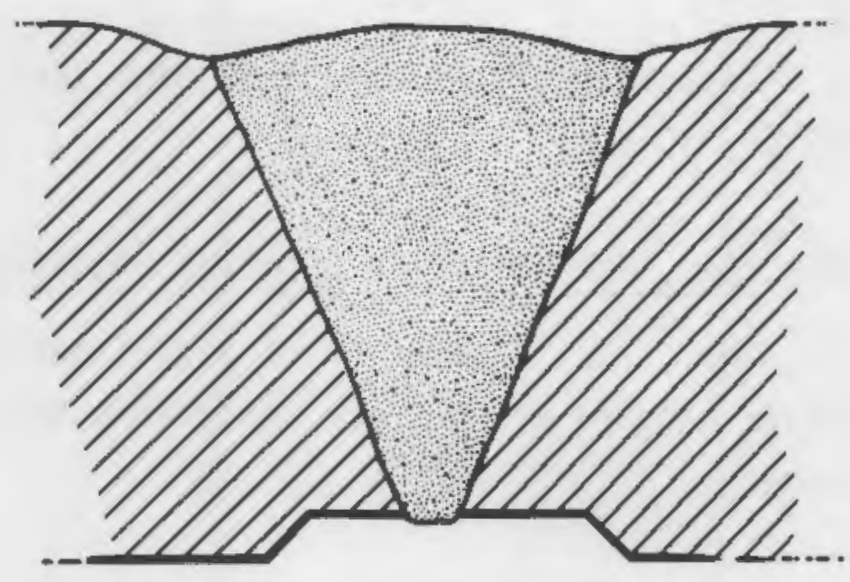

d) Overground

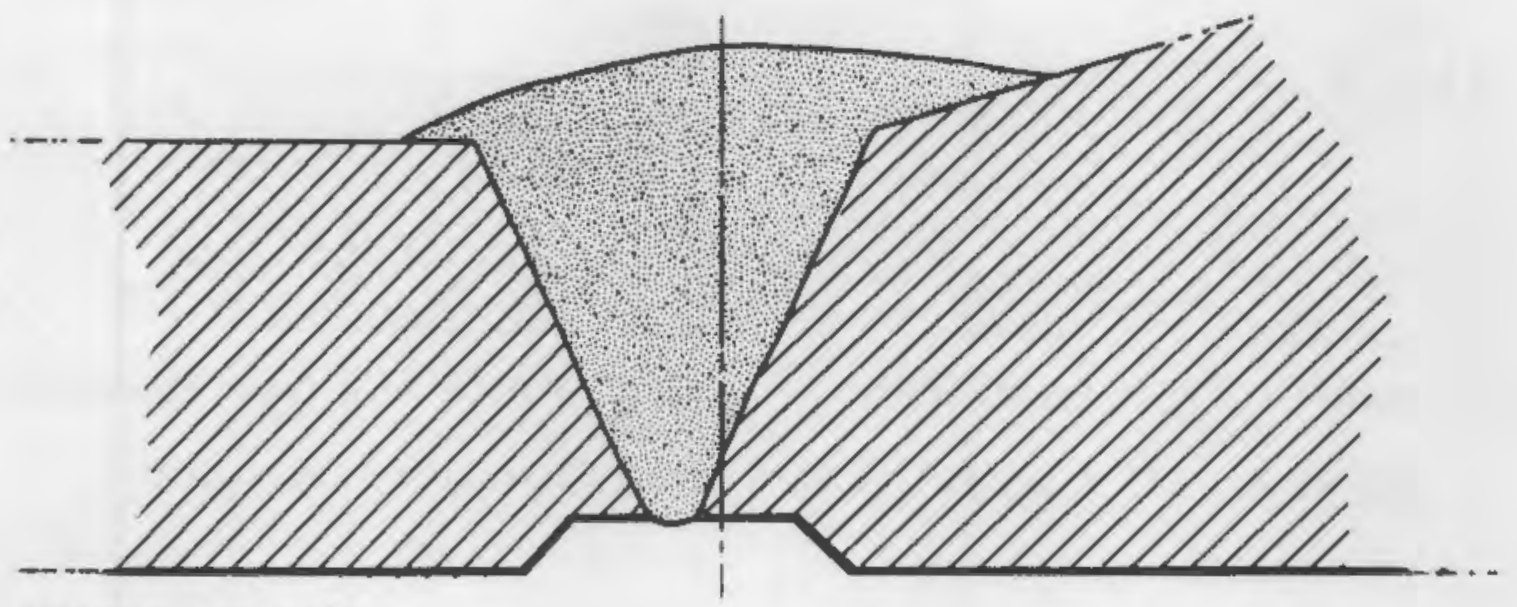

e) Unknown Centerline

FIGURE 3. Outer Diameter Geometry Cond it ions 
path weld root examination, or a $3 / 2 \mathrm{~V}$ path weld root examination when $1 / 2 \mathrm{~V}$ path examination is impossible. Full $V$ path examination is used for inspection of the upper weld crown area. Figure 4 shows $1 / 2 \mathrm{~V}$ and full $\mathrm{V}$ path ultrasonic weld examination. Respondents estimated that essentially $80 \%$ to $100 \%$ of the primary reactor coolant system welds were ground. New plants under construction have welds that are blended. 0lder operating PWR and BWR plants have a variety of conditions; the most common reported condition is with the crown ground flat with an edge height of approximately 0.03 in.

Typically, there are no special procedures used to compensate for severe diametrical shrinkage. Respondents indicated that shrinkage is usually not a problem in thick-wall pipe, but occurs more often in thin-wall (0.5-in. wall thickness or less) pipe.

Respondents indicated that pipe surface finish is of good quality (e.g., 125 to $250 \mathrm{rms}$ ).

\subsection{PIPE INNER DIAMETER GEOMETRY CONDITIONS}

The survey discussion of pipe inner diameter (ID) geometry included information on pipe counterbore conditions and problems resulting from counterbore geometry.

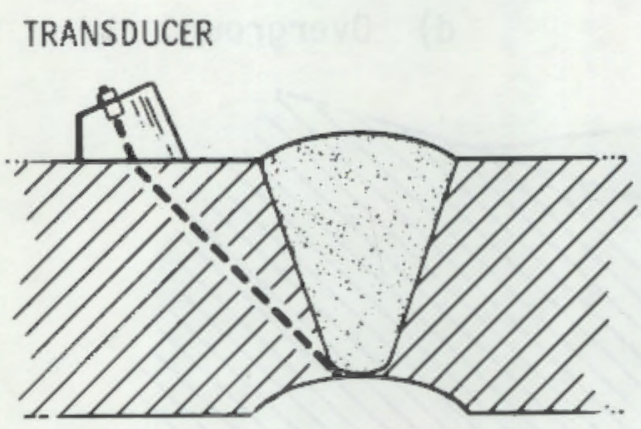

a) $1 / 2 \vee$ Path Weld Root Examination
TRANSDUCER

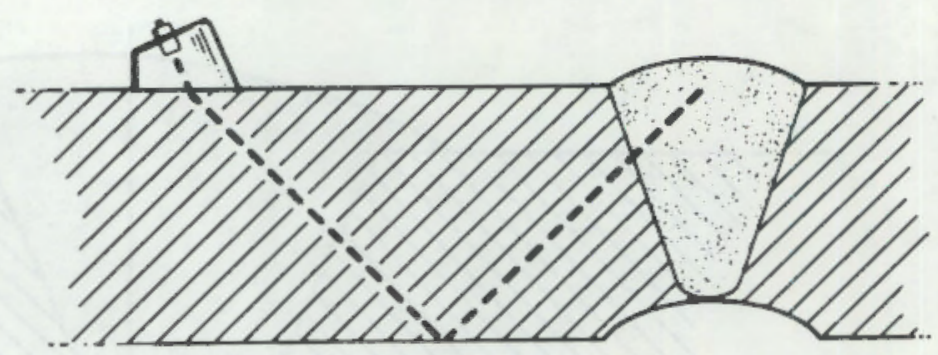

b) Full V Path Weld Crown Examination

FIGURE 4. $1 / 2 \mathrm{~V}$ and Full $\vee$ Path Ultransonic Weld Examination 
Figure 5 indicates the range of welded pipe counterbore conditions as sketched by the survey respondents. These sketches represent estimated worstcase and nominal-case conditions. As-built information on the counterbore is rarely available to the surveyed companies. Respondents indicated that design specification drawings are usually available; however, they questioned the usefulness of this information because of the optional methods currently allowed for pipe joint fabrication at commercial plants. In older operating plants, the design specification drawings are often unavailable.

In general, the survey respondents felt that their capability for accurately measuring counterbore geometry ranged from "poor" to "very poor." Most companies use a single-element transducer with a $0^{\circ}$ examination (thickness measurement) at $2.25 \mathrm{MHz}$ to $5 \mathrm{MHz}$. However, one respondent uses a dualelement, line-focused transducer. On occasion radiography is used where possible.

The availability of baseline information on geometric reflectors varies from "not very often", to, "40\% to $50 \%$ of the time" and "frequently available." Respondents indicated that the baseline information on geometric reflectors is generally correct. However, in one case where destructive analysis had been performed, one respondent reported that stress corrosion cracking was labeled as a geometric reflector. Counterbore geometry, weld root suck-up, and weld root drop-through were mentioned as key pipe ID concerns (see Figure 6). One respondent indicated that sometimes geometric indications are reported and sometimes they are not: if indications are not reported on the data sheet but are noted by plant inspection personnel, the reporting of the geometric indication in future in-service inspections is used as a check on the inspector.

Respondents were asked if they thought there was a need for a standard format for recording geometric indications. Several respondents saw no need for a standard format for recording geometric indications. Other respondents believed that a standard format is needed and that it should be a code requirement. 


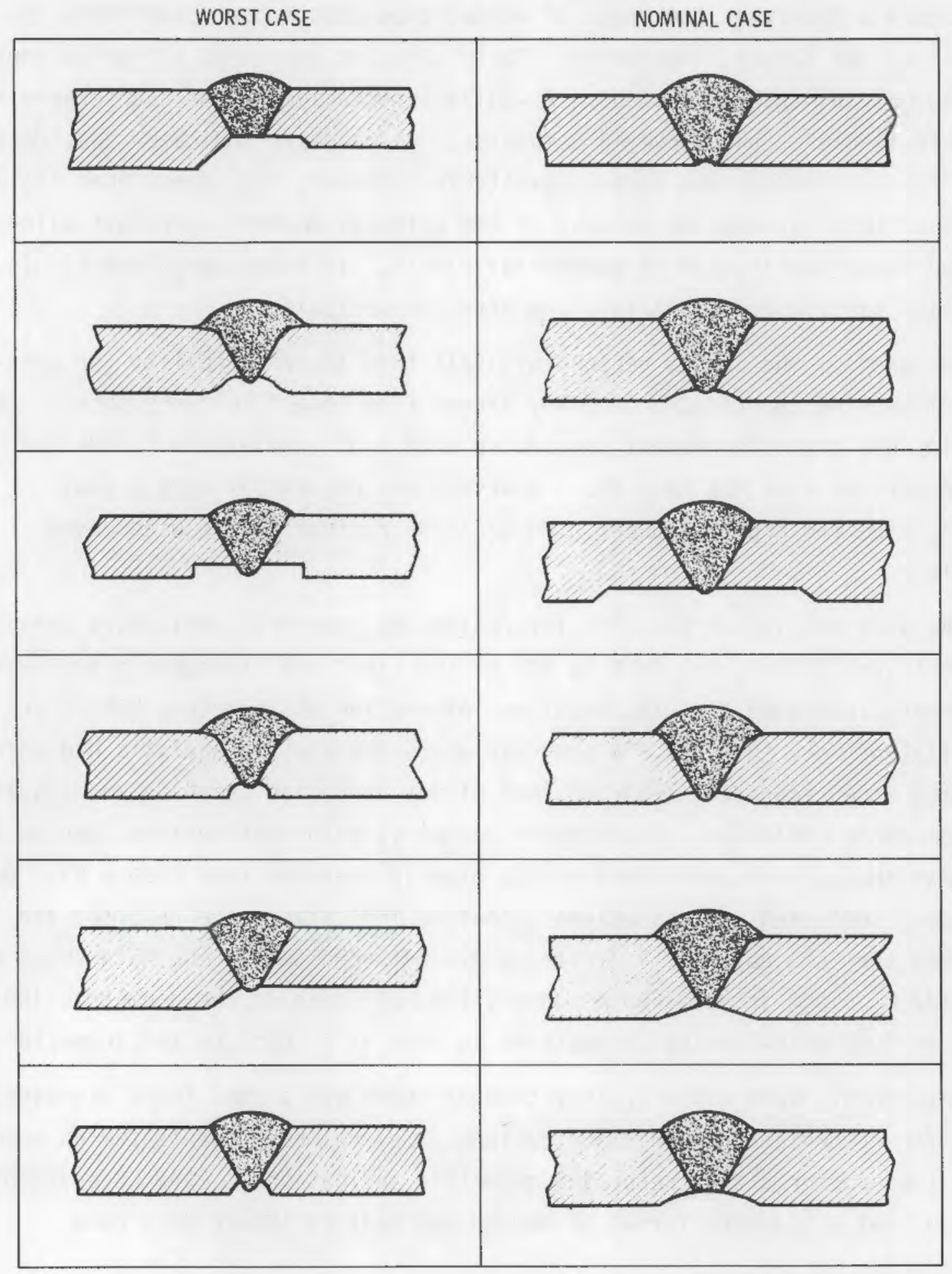

FIGURE 5. Pipe Counterbore Geometry Conditions 


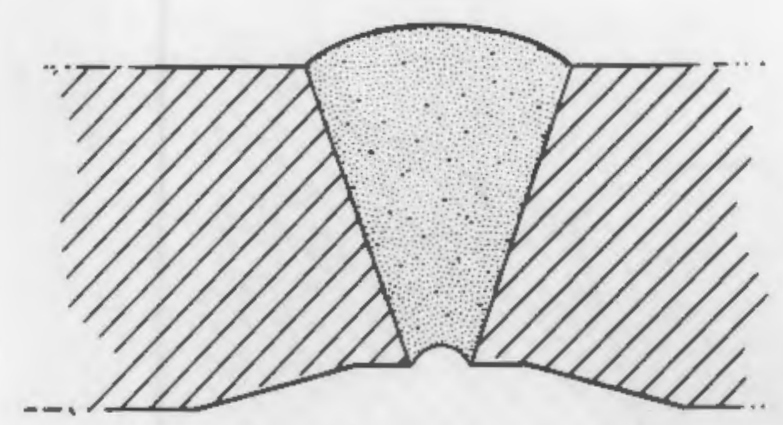

a) Root Suck-Up

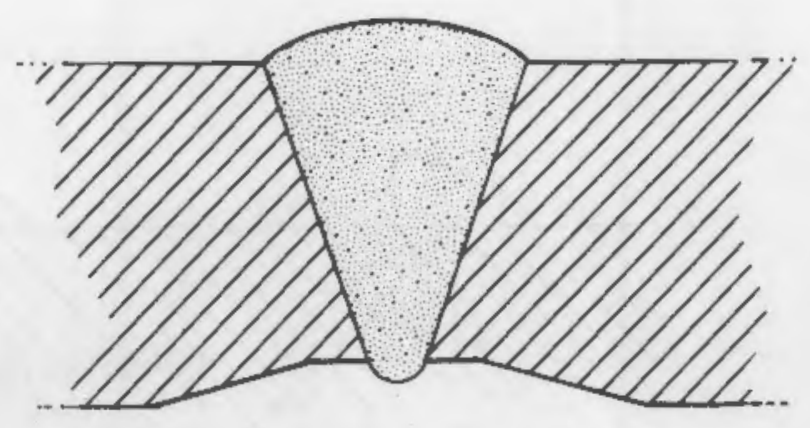

b) Root Drop-Through

FIGURE 6. Pipe Inner Diameter Suck-Up and Drop-Through Conditions

Those respondents that did not feel the need for a standard format stated that the recording of geometric reflectors is essentially a code requirement: the Code specifies recording of all defect-like indications which exceed a reference level. One respondent felt that all tests should be strip chart recorded for a permanent record of each examination.

Opinions varied concerning the value of baseline data gathered by different organizations. Responses ranged from "It should be valid if procedures and calibration blocks are the same," to "often very little value, since levels of recording and test procedure can be different," to "do not record geometry reflector for baseline."

Respondents were asked how they evaluate $3 / 2 \mathrm{~V}$ signal indications when the beam is incident on the conical section of the counterbore (see figure 7 ). Respondents indicated that they can get a $1 / 2 \mathrm{~V}$ examination of the weld root for the majority of primary system welds.

\subsection{CALIBRATION, INSPECTION, AND FLAW EVALUATIDN}

Calibration verification and inspection practices were discussed in the survey, and a series of questions were asked concerning flaw evaluation and recording methods.

Typical industry practice is to verify initial instrument calibration by recalibrating at least every four hours and/or at every operator change. Scan overlap during calibration/inspection is $10 \%$ to $25 \%$. Some skew is usually used 


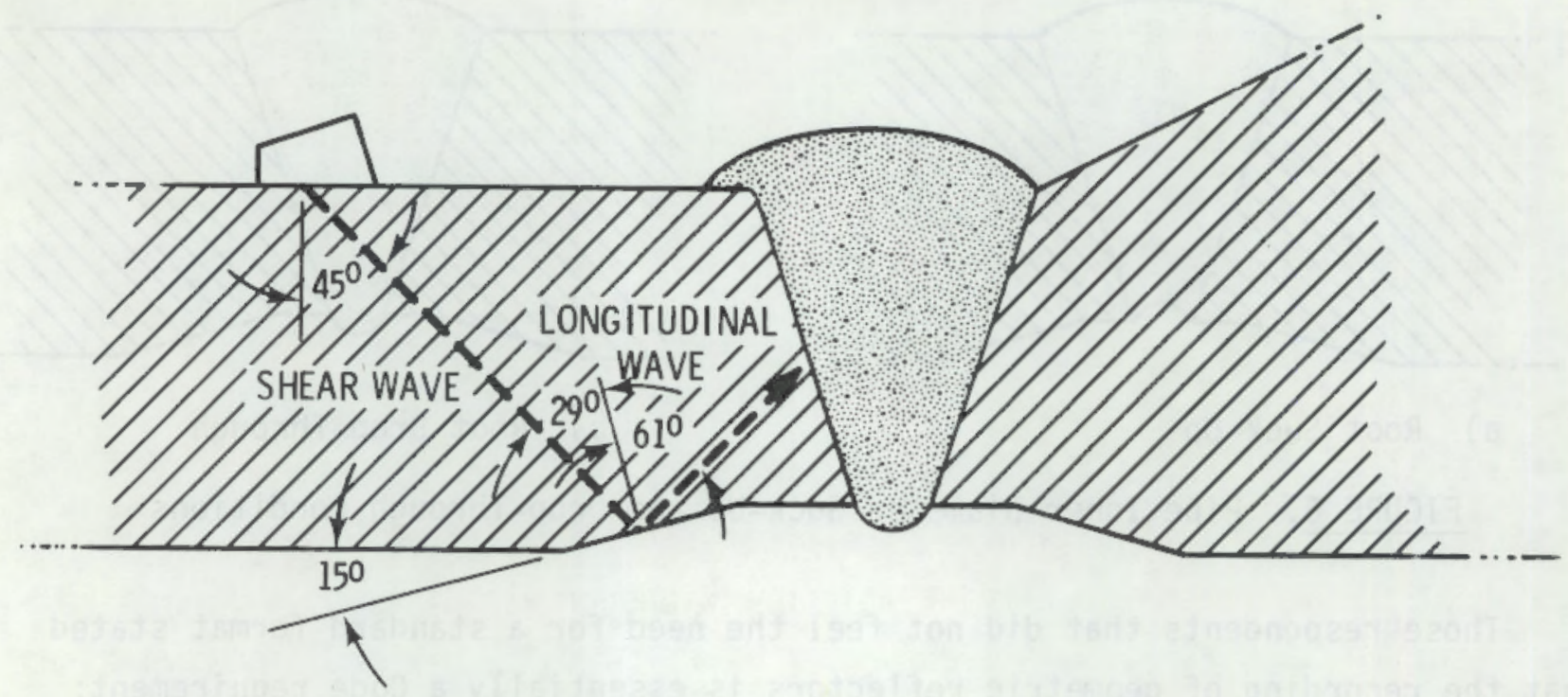

FIGURE 7. $3 / 2$ V Examination with the Beam Incident on the Conical Section of the Counterbore (mode conversion of shear to longitudinal wave at conical section of counterbore)

during calibration/inspection, but the amount is neither mandatory nor recommended. One company uses a $45^{\circ}$ skew for IGSCC inspection. The skew for ferritic pipe inspection ranges from $0^{\circ}$ to $20^{\circ}$.

In-practice flaw evaluation and recording methods were determined with the following questions.

1. What is the data recording procedure?

Most respondents record signal indications that are $50 \%$ of DAC or greater and evaluate indications at $100 \%$ of DAC. Several respondents investigate and note signals $20 \%$ and $25 \%$ of OAC. One procedure called for the recording of indications down to $20 \%$ of the maximum indicated amplitude. Taylor and Selby (1980) evaluated the change in inspection sensitivity and data recording requirements resulting in major changes of the ASME Boiler and Pressure Vessel Code Section XI between the 1974 and 1977 Editions. Also discussed are the U.S. Nuclear Regulatory criteria in effect at several plants.

2. What is the position accuracy on the pipe ID surface?

Estimated positional accuracy on the pipe surface during inspection varied from 0.02 to 0.2 in. 
3. What is the time metal path accuracy for $1 / 2 \mathrm{~V}$ and $3 / 2 \mathrm{~V}$ inspections? Estimates of time metal path accuracy for $1 / 2 \mathrm{~V}$ examination were as small as $0.01 \mathrm{in}$. and as large as 0.125 in. Estimates of time metal path accuracy for $3 / 2 \mathrm{~V}$ examination ranged from 0.02 to $0.2 \mathrm{in}$.

4. Are there supplemental tests? other angles, frequencies? Two-side evaluation? Finger damping?

Standard practice is to use a $45^{\circ}$ examination of each side of the weld. When a flaw is suspect, companies use $60^{\circ}$ and $70^{\circ}$ supplemental examinations. Finger damping is a common practice used to check on extraneous signals.

5. What methods do you use to call ID geometry? OD geometry?

For ID geometry, inspectors use reflector position (i.e., proximity to weid root) and the extent of indication (e.g., a $360^{\circ}$ single reflector often indicates geometry conditions). Signal shape and characteristics, plotting methods, and refracted angle conversion charts are also used. Inspectors use many of these techniques to determine DD geometry. Finger damping is a key test for $O D$ geometry.

6. When and how often do you call for radiography? How useful is radiography?

Inspectors call for radiography if they think that the ultrasonic test is inadequate for making a reliable inspection. The utility usually requests a radiograph if a flaw is called. One respondent calls for radiography if other radiographs are already on file (for comparison). Another calls for radiography if the inspector suspects IGSCC, which was estimated to occur about once per site inspection. The radiographs may then show weld spatter or can sometimes detect IGSCC. One inspector noted that radiography is not usually used for in-service inspection, while others indicated that radiography is used quite often. Most respondents judged radiography to be useful in some cases, but they varied in their estimate of its effectiveness. 
7. When do you call for penetrant?

Most inspectors call for penetrant when ultrasonic inspection indicates suspect surface anomalies or through-wall indications. One company calls for penetrant when the weld has only single-side access.

8. What supplemental information do you call for and what is your confidence in them?

A variety of supplemental information is used but not necessarily all the time: design drawings, radiographic testing records, welding procedures, weld specifications, weld preparation data, previous ultrasonic inspection data, contour gauge measurements, as-built drawings, or other information may be available. The consensus seems to be that such information can be helpful although its reliability must be suspect, especially with older plants.

\subsection{EXPERIENCE WITH DISSIMILAR METAL WELDS}

Respondents were asked about their experience with dissimilar metal welds (bimetallic and trimetaliic). Companies indicated that the bimetallic (e.g., carbon to stainless) and trimetallic welds (e.g., carbon to Inconel to stainless) produce many indications (particularly along the weld fusion zone interface) that complicate ultrasonic examination. Respondents try to use the most attenuative material for standards, but standards vary. One respondent indicated that it is not uncommon to experience a 20-or 30-decibel loss in signa! amplitude when looking through the weld zone at known artificial reflectors positioned in the heat-affected zone. Training with dissimilar metal weld standards is a common practice. Test confidence in detection of flaws was estimated at $50 \%$ to $60 \%$. 


\subsection{CONCLUSIONS}

The ultrasonic examination procedures used for in-service inspection and evaluation of Class 1 reactor coolant system pressure-retaining welds are essentialiy the minimum requirements documented in the 1974 edition of the ASME Code, Section XI. Special ultrasonic examination procedures for the detection of inter-granular stress corrosion cracking and flaws in centrifugally cast stainless steel are more variable. Major differences occur in the examination techniques, the methods and procedures used for evaluating indications after detection, and the method and extent of data recording.

A major difference of opinion exists as to the need for recording geometric reflectors during preservice inspection (PSI). Some organizations do not record geometric indications during PSI. When geometric indications are recorded, their usefulness for ISI is sometimes questioned because there is no standard format for data recording. Researchers at PNL believe that a welldocumented PSI would substantially improve the reliability of in-service inspections.

A wide range of nominal and worst-case counterbore geometry conditions was reported. Many of these conditions are unacceptable according to Section III of the ASME Code (ASME 1977b) and could lead to highly variable inspection results. As-built information on counterbore geometry is seldom available and is difficult to determine by nondestructive evaluation methods.

Only one company performs periodic evaluations on search units used for ISI. Few organizations make any search unit characterization other than the manufacturer's test report (RF waveform and frequency spectrum). Many respondents feel that extensive search unit or instrument characterization has no substantial benefit. Research efforts at PNL have indicated substantia] differences in the performance of uTtrasonic instruments and search units. Researchers at PNL believe that repeatable test results can be obtained only with we11-characterized search units and instruments. Evaluations are in progress to determine the magnitude of these test variables. 
The respondents uniformly agree to a high-confidence level (greater than 90 ) in their ability to detect flaws in ferritic steel piping. For flaws in austenitic stainless steel piping the confidence estimate is lower -60 to 85 for flaws from 10 to 25 of through-wall thickness and approximately 90 for flaws greater than 25 of through-wall thickness. Confidence for dissimilar metal weld joints ranges from 50 to 60 because of the high attenuation and spurious reflectors common to these welds. Confidence levels for centrifugally cast stainless steel are highly variable with one organization expressing a relatively high confidence (due to their independent research) compared to others who expressed no confidence. These levels of confidence should not be construed to have any statistical basis because they are personal opinions based on individual experiences. However, these opinions do give a realistic indication of the relative degrees of difficulty associated with inspection of these materials.

Over the last several years the utilities, the U.S. Nuclear Requlatory Commission, the Electric Power Research Institute, and other private nondestructive testing organizations have been increasingly aware of the need to improve both qualitative and quantitative nondestructive measurement capabilities for inspection of $C l$ ass I piping systems at conmercial nuclear power plants. Several of the more difficult areas of pipe weld inspection have been noted here. The review showed that there are noted differences in the aspracticed ultrasonic inspection methods and procedures used at commercial nuclear power plants. Researchers at PNL believe that further documentation of these practices will substantially benefit both NDE practitioners and regu1 atory personnel by providing technical information that will increase and improve the understanding of current Code inspection practices. 


\subsection{RECENT EXPERIENCES}

The preponderance of data compiled in this report was collected during 1979 and 1980. Since that time, the state of practice has progressed, particularly in the areas of IGSCC detection and the inspection of centrifugally cast stainless stee] (CCSS). Recent evaluations of the state of practice in the areas of IGSCC and CCSS are reported below.

\section{- 4.1 IGSCC DETECTION}

Recent developments in the area of IGSCC detection and characterization include: increased sensitivity, better transducer selection, improved training and experience, and improved "rule-of-thumb" techniques for separating IGSCC from geometric responses. Many organizations have lowered their threshold for evaluation to $50 \%$ of a side-drilled-hole DAC or $20 \%$ of a $10 \%$ notch DAC. These are approximately the same sensitivities for 0.5-in. wall thickness (Taylor and Selby 1980). Others, however, are still using $100 \%$ of a $10 \%$ notch DAC; this is a 14- $\mathrm{BB}$ difference in sensitivity. It is our understanding that the $20 \%$ of a side-drilled-hole DAC is the required evaluation threshold in Japan. A $5 \%$ notch is used by some companies. The $5 \%$ notch yields a DAC approximately 2 to $3 \mathrm{~dB}$ more sensitive than a $10 \%$ notch.

There is still considerable diversity of opinion as to which transducer is most appropriate for the detection of IGSCC. Those most favored include:

a dual 1.5-MHz transducer; a 0.375-in.-dia., 1.5-MHz single-element transducer; a 0.25-in.-dia., 2.25-MHz transducer; and 0.5-in.-dia., 2.25-MHz transducer. of the two available types of dual units, the one with broader bandwidth is most popular. Stated reasons for these choices include:

- "1.5 MHz yields a larger response relative to DAC."

- "2.25 MHz yields higher flaw response amplitude relative to geometric root responses."

These are contradictory statements. Due to the rough and branched nature of IGSCC, it is expected that the 1.5-MHz units will yield higher responses than the 2.25-MHz units, as the roughness represents a smaller fraction of the wave 
length. Better discrimination against geometric reflectors (root) might be expected as the 2.25-MHz sound beam is more highly collimated and will experience more attenuation passing through the cast structure of the weld metal. The most appropriate transducer will depend on application, i.e., wall thickness, geometrical conditions, and reporting threshold.

The development of the graphite wool technique (Kawamoto 1980) has allowed the fabrication of test samples which cracks similar to those found in-service. The availability of these samples for training and test development should substantially improve the reliability of IGSCC flaw detection.

Over the past five years considerable experience has been gained in evaluating IGSCC flaws. The principal difficulty in evaluating IGSCC flaw indications is separating them from geometrical indications (primarily root reflections). There is general agreement that the most appropriate method for evaluating indications is very careful plotting of the indications. This requires precise location of the root as well as counterbore by normal-beam measurements. Any indication that plots on the near side of the root centerline should be highly important in this determination. Most organizations claim axial plotting accuracy of less than $0.1 \mathrm{in}$.

It has been stated that "IGSCC will occur $1 / 4$ to $1 / 2 \mathrm{in}$. from the fusion line, depending on thickness." Exceptions have been observed, i.e., cracks located directly adjacent to the root. The applicability of the $1 / 4 \mathrm{in}$. "rule of thumb" is questionable. Other characteristics of IGSCC that aid in its identification include:

- Orientation: it can occur in any orientation from circumferential to axial.

- Flaws are generally discontinuous but not always.

- The search may be skewed $\pm 10^{\circ}$ with relatively little loss in amplitude compared to geometric relectors (however, this is not always true).

- Sixty-degree inspections using a higher frequency (4 or $5 \mathrm{MHz}$ ) are often helpful in evaluating indications. 


\subsection{CENTRIFUGALLY CAST STAINLESS STEEL}

Cast stainless pipe presents a major unresolved problem area because of its high attenuation and anisotropic grain structure. However, recent advances in search unit design promise improved inspection performance. Characteristics of these units include:

- dual units mounted on a plastic shoe

- $1 \mathrm{MHz}$ operating frequency with 40 to $45^{\circ}$ longitudinal wave

- high damping, i.e., short pulse.

The dual-element design minimizes near-surface ringdown. The short pulse allows better visual discrimination between flaw signals and grain noise. One$\mathrm{MHz}$ longitudinal is about the only wave mode and frequency that can penetrate (2- to 3-in. wall thickness pipe) and still see flaws.

In using longitudinal waves for detection of surface-connected cracks, it should be understood that approximately $85 \%$ of the incoming signal is mode converted to shear waves and lost. Calibrations using side-drilled holes do not represent this condition as no mode conversion takes place. On the other hand, it is often not possible to detect a $10 \%$ calibration notch (or for that matter, a corner reflection from the end of the block), because of the high noise level. However, fatigue flaws in test blocks can often be detected. The roughness of the fatigue flaws aid in their detection. Since neither the side-drilled hole or $10 \%$ notch are entirely appropriate, it may be advisable to turn up the gain to 20 or $30 \%$ screen height for general structural noise and to look for backsurface-traveling indications. 0perator training on real crack samples is highly advisable in this case.

\subsection{FUTURE TRENDS}

The single most often stated desire of inspectors was to be able to train on real cracks in realistic mock-up samples. The technology for fabricating crack samples is available and a limited number of samples are available through the Electric Power Research Institute and PNL. Wider distribution of these types of samples in the future could substantially improve inspection performance. 


\section{REFERENCES}

ASME. 1977a. ASME Boiler and Pressure Vessel Code, Section XI, Rules for Inservice Inspection of Nuclear Power Plant Components. July 1977, with addenda through winter of 1978. American Society of Mechanical Engineers.

ASME. 1977b. ASME Boiler and Pressure Vessel Code, Section III, Nuclear Power Plant Components-Class I. July 1977, American Society of Mechanical Engineers.

Becker, F. L. 1981. Integration of NOE Reliability and Fracture Mechanics Phase I Report. NUREG/CR-1696. Prepared for the U.S. Nuclear Regulatory Commlmission by Pacific Northwest Laboratory, Richland, Washington.

Birks, A. S., and W. E. Lawrie. 1978. "Search Unit Specification for Improved Repeatability of U1trasonic Examinations." In Proceedings of an International Conference on Nondestructive Evaluation on the Nuclear Industry.

Buchanan, R. A. 1975. "Analysis of the Nondestructive Examination of PVRC Plate-Weld Specimen $251 \mathrm{~J}$-Part A." Welding Research Council Bulletin 221.

Kawamoto, T. 1980. "Production of Controlled Intergranular Stress Corrosion Cracking in Large Diameter Pipe." In "Nondestructive Evaluation Program Progress in 1980." G. J. Dau et al., eds., EPRI NP-1690-Sr.

Serabian, S., and W. E. Lawrie. 1977. "A Detection Model for Pulse Echo Ultrasonics." Paper presented at the ASNT Fall Meeting, September 1977.

Taylor, T. T., and G. P. Selby. 1980. Evaluation of ASME Section XI Reference Levei Sensitivity for Initiation of Ultrasonic Inspection Examination. NUREG/CR-1957, prepared for the U.S. Nuclear Regulatory Commission by Pacific Northwest Laboratory, Richland, Washington. 
APPENDIX

TABLES OF DETAILED SURVEY RESPONSES 


\section{APPENDIX}

\section{TABLES OF DETAILED SURVEY RESPONSES}

The following pages present detailed information gathered in the state-ofpractice survey. Representatives of four utilities, five private inspection organizations, and three domestic reactor manufacturers were interviewed and their responses recorded. The interviews included questions about ultrasonic in-service inspection of Class I system piping in nine subject categories:

1. Utility, Inspection Organization, and Reactor Vendor Experience

2. Selection and Performance Verification of Transducers

3. Manual Piping Inspection Practices

4. Inspection Practices for Ferritic and Stainless Steel Pipe

5. Experience with Centrifugally Cast Stainless Steel Pipe

6. Automated Inspection Practices

7. Pipe Outer 0iameter Geometry Conditions

8. Pipe Inner Diameter Geometry Conditions

9. Calibration, Inspection, and Flaw Evaluation

The names of the survey respondents and their respective organizations are not included here. Within each of the ten subject categories survey respondents are designated by letter (A, B, and so on). These letter designations are consistent within subject categories but do not necessarily correspond between categories. The purpose of reporting these individual responses is not to identify certain inspection practices with specific organizations but rather to show the range of experience and practices: instances where opinions agree or diverge, where procedures are similar or vary widely, where problems are recognized or uncertain.

The trends of the responses are summarized and interpreted in Section 2, State of Practice Survey Results, and Section 3, Conclusions, of the main document. 
1. Utility, Organization, Inspection and Reactor Vendor Experience

\begin{tabular}{|c|c|c|c|}
\hline $\begin{array}{c}\text { Survey } \\
\text { Respondent }\end{array}$ & $\begin{array}{l}\text { Number of Units Inspected, } \\
\text { (Operat ing/Under Construction) }\end{array}$ & $\begin{array}{l}\text { Percent Inspected by } \\
\text { Outside Agency? }\end{array}$ & $\begin{array}{l}\text { Inspection mode } \\
\text { Utility? }\end{array}$ \\
\hline A & PWR $(2 / 4)$, BWR $(7 / 0)$ & yes $\sim 95 \%$ & $\begin{array}{l}\text { only for special } \\
\text { problems }\end{array}$ \\
\hline B & $20 \mathrm{BWRs} /$ Year & NA & NA \\
\hline$c$ & PWR $(0 / 2)$, BWR $(1 / 0)$ & $<40 \%$ & $\begin{array}{l}\text { only for } \\
\text { special } \\
\text { problems and } \\
\text { followup to } \\
\text { PSI and ISI }\end{array}$ \\
\hline D & 30 to 40 inspections/year & NA & NA \\
\hline$E$ & PWR $(0 / 8)$, BWR $(3 / 6)$ & $95 \%$ & $\begin{array}{l}\text { only for } \\
\text { special } \\
\text { problems }\end{array}$ \\
\hline $\mathrm{F}$ & 20 to $30 \mathrm{PWRs} /$ year & NA & NA \\
\hline G & PWR $(2 / 2), 8 W R(1 / 0)$ & $95 \%$ & $\begin{array}{l}\text { usually } \\
\text { participates } \\
\text { with special } \\
\text { problems }\end{array}$ \\
\hline Survey & \multicolumn{3}{|c|}{ Inspections with Centrifugally Cast Stainless Steel (CCSS) Piping } \\
\hline Respondent & Has ISI been performed by UT? & \multicolumn{2}{|l|}{ Is UT Inspection Planned? } \\
\hline A & no & \multicolumn{2}{|l|}{ yes } \\
\hline B & NA & \multicolumn{2}{|l|}{ NA } \\
\hline C & $\cdots$ & \multicolumn{2}{|l|}{--} \\
\hline D & NA & \multicolumn{2}{|l|}{ NA } \\
\hline $\mathrm{E}$ & no & \multicolumn{2}{|l|}{ yes } \\
\hline$F$ & yes & \multicolumn{2}{|l|}{ yes } \\
\hline G & yes & \multicolumn{2}{|l|}{ yes } \\
\hline
\end{tabular}




\section{Utility, Organization, Inspection and Reactor Vendor Experience (contd)}

Survey Number of plants inspected with Number of Inspections for Intergranular Respondent CCSS Primary Coolant Piping Stress Corrosion Cracking (IGSCC) in 1978

\begin{tabular}{|c|c|c|}
\hline A & unknown & -- \\
\hline B & none & $\begin{array}{l}\text { All tests on stainless pipe are done to } \\
\text { detect stress corrosion. }\end{array}$ \\
\hline C & none & - \\
\hline D & none & no specific IGSCC inspections \\
\hline E & 4 & -- \\
\hline $\mathrm{F}$ & 8 to 10 & $\begin{array}{l}\text { Inspections at } 4 \text { plants found nothing; } \\
\text { some evidence of stress corrosion in the } \\
\text { sensitized area was found at two plants. }\end{array}$ \\
\hline
\end{tabular}




\section{Selection and Performance Verification of Transducers}

Survey What are your general criteria Respondent

A

B

C

D

E

$\mathbf{F}$

G

H for selecting transducers?

past experience; response;

signal-to-noise ratio

past experience; response;

signal-to-noise ratio

past experience; signal-to-

noise ratio; resolution

past experience; procedures

past experience; response;

signal-to-noise ratio

Criteria are determined by procedure during procedure development tests; if tests are limited or non-existent, then criteria are determined by liason with experienced fieldinspectors.

past experience

past experience; recommendation of procedure deve iopment engineer

past experience; response; signal-to-noise ratio
What methods are used initially to verify transducer performance?

a) center frequency, beam profile

certification data from manufacturer

certification data from manufacturer

certification data from manufacturer

certification data from manufacturer

certification data from manufacturer

in-house laboratory certification

certification data from manufacturer

none

A transducer that gives a good calibra$t i o n$ is assumed good. There is not much merit in requiring a beam profile, and the inspection frequency is not critical. "He are trying to make a science out of an art." 


\section{Selection and Performance Verification of Transducers (contd)}

\begin{tabular}{|c|c|c|c|}
\hline $\begin{array}{c}\text { Survey } \\
\text { Respondent }\end{array}$ & $\begin{array}{l}\text { What methods are used initially to verify } \\
\text { performance? } \\
\text { b) near-field, distance amplitude correct }\end{array}$ & $\begin{array}{l}\text { transducer } \\
\text { ion (DAC) }\end{array}$ & c) Sensitivity \\
\hline A & $\begin{array}{l}\text { For thin-wall pipe the transducer is } \\
\text { checked on ID notch; side-drilled holes } \\
\text { (SDH) on calibration blocks are used for } D\end{array}$ & & SDHs are used. \\
\hline B & There is no near-field check; DAC uses SOH & & SOHs are used. \\
\hline $\mathrm{C}$ & There is no near-field check; DAC uses SDH & & SDHs are used. \\
\hline 0 & There is no near-field check; DAC uses SDH & & SDHs are used. \\
\hline $\mathrm{E}$ & There is no near-field check; DAC uses SDH & & SOHs are used. \\
\hline $\mathrm{F}$ & $\begin{array}{l}\text { OAC uses SDH; a } 7 \text { - to 9-point caitibration } \\
\text { is used. }\end{array}$ & curve & SOHs are used. \\
\hline G & $\begin{array}{l}\text { DAC uses SOH; a } 7 \text { - to 9-point calibration } \\
\text { is used. }\end{array}$ & curve & SDHs are used. \\
\hline$H$ & There is no near-field check; DAC uses SDH & & SDHs are used. \\
\hline I & There is no near-field check; DAC uses SDH & & SDHs are used. \\
\hline $\begin{array}{c}\text { Survey } \\
\text { Respondent }\end{array}$ & $\begin{array}{l}\text { What methods are used initially to verify } \\
\text { transducer performance? } \\
\text { d) resolution }\end{array}$ & e) angle & f) others \\
\hline A & SDHs are used. & I IW & $\begin{array}{l}\text { Beam spread is checked } \\
\text { with SDH. Tests are } \\
\text { made on surface } \\
\text { notches to get sone } \\
\text { feel for SoH versus } \\
\text { notches. }\end{array}$ \\
\hline B & SDHs are used. & I I w & none \\
\hline C & SOHs are used. & I I w & none \\
\hline D & SDHs are used. & II $W$ & none \\
\hline$E$ & SOHs are used. & I I'w & none \\
\hline $\mathrm{F}$ & SOHs are used. & II' & none \\
\hline G & SDHs are used. & I I $W$ & none \\
\hline H & none & I IW & none \\
\hline I & -- & -- & -- \\
\hline
\end{tabular}




\section{Selection and Performance Verification of Transducers (contd)}

Survey What is used to control and monitor Respondent transducer performance?

A Although there are no periodic checks, records of all transducer certifications are kept. Transducers usually "deteriorate rapidly" as noted by the need for significant increase in gain.

B Each successful calibration monitors performance. Usually a significant increase in gain indicates problems. There are no periodic checks.

C Although there are no periodic checks, records of a 11 transducer certifications are kept.

D In 1976, 15 transducers were sent back to the manuf acturer for checking. All tests confirmed transducers $0 \mathrm{~K}$.

E Calibration block checks perf ormance.

F Certifications are kept with each transducer. They are recertified every six months.

G Experience teils them when transducer is about to fail; they are using a 7- to 9-point calibration block.

$\mathrm{H} \quad$ Each time a transducer is used, it is checked on a calibration block.

I Calibration block checks performance.
What is the est imated useful lifetime for an angie-beam transducer?

Utility use: 4 to 5 years;

ISI company: 2 years

4 years. Dropped transducers are the biggest problem.

Utility use: 4 or 5 years;

ISI company: 2 years

2 years. Special units may last

4 or 5 years.

2 to 3 years

2 years

2 years

2 years

2 to 3 years 


\section{Manual Piping Inspection Practices}

\begin{tabular}{|c|c|c|}
\hline $\begin{array}{c}\text { Survey } \\
\text { espondent }\end{array}$ & $\begin{array}{l}\text { What make and model instrument is used } \\
\text { for manual piping inspection? }\end{array}$ & Is the unit modified? \\
\hline A & $\begin{array}{l}\text { mostly Sonic Mark I; some Branson 301; } \\
\text { Nortec } 131 \text { D }\end{array}$ & no \\
\hline B & 6 Nortec 1310; 1 Sonic Mark I & no \\
\hline C & Sonic Mark I; KB USM-2; Nortec 1310 & modified Sonic Mark I \\
\hline D & $\begin{array}{l}\text { mostly Sonic Mark I; Sonic Mark IV; } \\
\text { Nortec 1310; KB USM-2; Branson } 303\end{array}$ & no \\
\hline E & Sonic Mark I; Sperry UJ; KB USL 31 and 32 & yes \\
\hline$F$ & $\begin{array}{l}\text { Magnaflux PS-710; KB USM-2; KB USIP-11; } \\
\text { Magnaflux PS-702A }\end{array}$ & no \\
\hline G & $\begin{array}{l}\text { Sonic Mark I is vast majority; I each of } \\
\text { a few other makes }\end{array}$ & no \\
\hline$H$ & KB USM-2 & no \\
\hline I & Branson 303; KB USIP-11; Sonic Mark I & no \\
\hline J & K8 USM-2; Branson 303 & no \\
\hline k & $\begin{array}{l}\text { Nortec 13l; Sonic Mark I; Branson 303; } \\
\text { Sonic Mark IV }\end{array}$ & no \\
\hline
\end{tabular}

Survey Respondent If modified, what are the modifications?

$\begin{array}{ll}\text { A } & -- \\ \text { B } & \text { 20-inch range gate added for thick-wall } \\ \text { inspection } & \\ \text { D } & \text {-- } \\ \text { E } & \text { The KB USL } 31 \text { and } 32 \text { has additional circuitry and vertical control } \\ \text { adjustment changes } & \\ \text { F } & -- \\ \text { H } & - \\ \text { I } & -\end{array}$

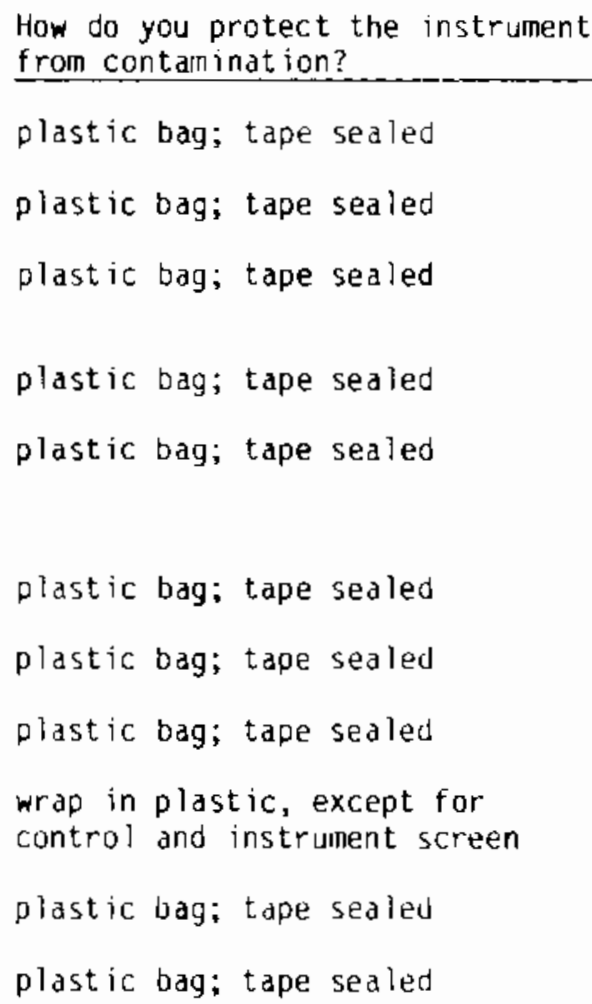




\section{Manual Piping Inspection Practices (contd)}

$\begin{array}{cl}\text { Have these precautions for prevent ing } \\ \text { instrument contamination resulted in } \\ \text { Survey } & \begin{array}{l}\text { any change in instrument performance? } \\ \text { Respondent }\end{array} \text { Has this been checked? }\end{array}$

A No; calibration is completed with the instrument in the bag.

B

C no

D No; calibration is completed with the instrument in the bag.

E No; older units are more affected by thermal changes.

G

H Generally no; higher temperatures can cause problems.

I No; calibration is completed with the instrument in the bag

J

no

K

no
Is the performance of the instrument checked after decontamination or after an accident such as dropping or rough handling?

Yes, for rough handling or after dropping; the instrument is checked before decontamination.

The instrument is checked after dropping and before it leaves the inspection area.

Yes; vertical and horizontal linearity are rechecked.

yes

Yes; the instrument is checked after rough handling. The instrument is calibrated before and after examination.

The instrument is checked after rough handling but not after decontamination.

The instrument is checked after rough handling but not after decontamination.

Operational performance checkout is required before inspection; the instrument is then calibrated before it leaves the inspection area.

yes 


\section{Manual Piping Inspection Practices (contd)}

Survey Is electronic DAC used for manual Respondent inspection? Automatic inspection?

$\begin{array}{ll}\text { A } & \text { no/no } \\ \text { B } & - \\ \text { C } & \text { no/yes } \\ \text { D } & \text { no/no } \\ \text { E } & \text { no/yes (vessel on ly) } \\ \mathrm{F} & \text { no/no } \\ \text { G } & \text { no/yes } \\ \text { H } & \text { no/yes and no } \\ \text { I } & \text { no/yes } \\ \text { J } & \text { no/no } \\ \mathrm{K} & \text { no/yes }\end{array}$

Do you follow periodic calibration or measurement requirements not specified by Code?

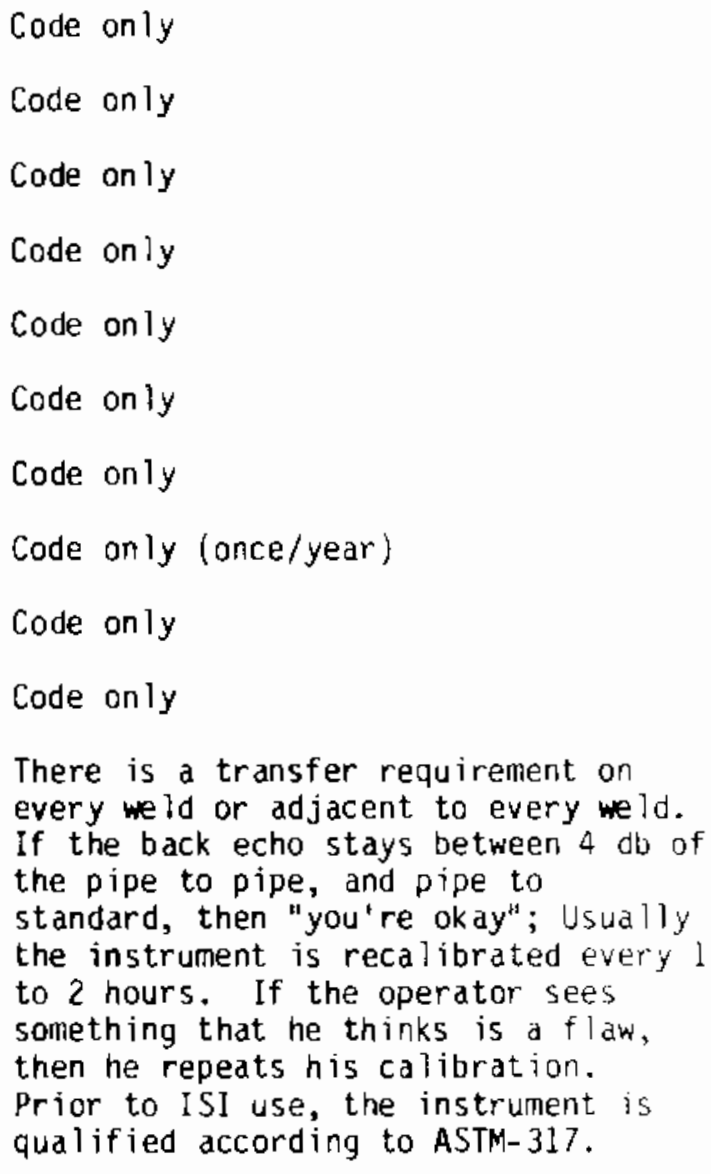

Code only

Code only

Code only

Code only

Code only

Code only

Code only

Code anly (once/year)

Code only

Code only

There is a transfer requirement on every ld or adjacent to every ld. If the back echo stays between $4 \mathrm{db}$ of the pipe to pipe, and pipe to standard, then "you're okay"; Usually the instrument is recalibrated every 1 to 2 hours. If the operator sees something that he thinks is a flaw, then he repeats his calibration. Prior to ISI use, the instrument is qualified according to ASTM- 317. 


\section{Manual Piping Inspection Practices (contd)}

Survey Are there requirements on pulser Respondent

$$
\text { A }
$$

no

B

C

D

E

$\mathrm{F}$

G

I

J

K

No; on ly the manufacturer's specs and recommendations are used.

No; a narrow band is used for weld exam; a wide band is used for thickness.

no

no

No; only the manufacturer's specs and recommendations are used.

$\mathrm{H} \quad$ No; only the manufacturer's specs and recommendations are used.

No; on ly the manufacturer's specs and recomendations are used.

no

no
If an external recording device is used, how is it calibrated?

none used

none used

none used

none used

none used

None used for manual inspection;

Strip charts and a computer are used to record amplitude and time for automated inspections.

none used

none used 


\section{Manual Piping Inspection Practices (contd)}

Survey Does your instrument Respondent require warm-up time?

A.

D None, although the instrument is on 2 to 5 minutes before the operators are ready.

E

No warm-up is required by the written procedure; however, 5 or 10 minutes is typical warm-up time.

No warm-up is required by the written procedure; however, 10 to 15 minutes is typical warm-up time.

G yes: 30 minutes

H yes: 15 minutes

I yes: 30 minutes for manual inspection, 1 hour for automated inspection.

3 yes: 4 to 5 minutes

K
Have you noted any problems with instrument stability, sensitivity, etc., due to warm-up time, battery charge, or line voltage fluctuation?

Yes; there is a $3-d B$ difference between initial calibration (just after turning instrument on) and later calibration check. The instrument aiways runs on batteries.

$-$

None; batteries are used.

none

none

none

Initially some problems occurred with batteries; new batteries for each major inspection eliminated the problem. Line voltage changes did cause problems; inspectors had to use a generator for automatic inspection at some sites.

None; batteries are used.

Not after warm-up; usually there are no line voltage problems.

none

none 


\section{Inspection Practices for Ferritic and Stainless Steel Pipe}

\begin{tabular}{|c|c|c|}
\hline $\begin{array}{l}\text { Survey } \\
\text { espondent }\end{array}$ & $\begin{array}{l}\text { What search units do you use for } \\
\text { ferritic pipe inspection? } \\
\text { a) up to } 10-\text { in. dia }\end{array}$ & b) 10- to $20-i n$. dia \\
\hline A & $1 / 4$ in. to $1 / 2 \mathrm{in.}, 2.25 \mathrm{MHz}, 45^{\circ}$ & $\begin{array}{l}1 / 2 \text { in. dia or } 1 / 2 \text { in. } x 1 \text { in., } \\
2.25 \mathrm{MHz}, 45^{\circ}\end{array}$ \\
\hline B & $1 / 4$ in. $x 1 / 4$ in., $2.25 \mathrm{MHz}, 45^{\circ}$ & 1 in. $x 1 / 2$ in., $2.25 \mathrm{MHz}, 45^{\circ}$ \\
\hline $\mathrm{C}$ & $1 / 2$ in. dia, $2.25 \mathrm{MHz}, 45^{\circ}$ & -- \\
\hline D & -- & -- \\
\hline$E$ & $1 / 4$ or $1 / 2$ in. dia, $2.25 \mathrm{MHz}, 45^{\circ}$ & $1 / 2$ in. dia, $2.25 \mathrm{MHz}, 45^{\circ}$ \\
\hline $\mathrm{F}$ & $\begin{array}{l}\text { 1/4 in. to } 3 / 8 \text { in. to } 1 / 2 \mathrm{in.} \\
\text { dia, } 2.25 \mathrm{MHz}, 45^{\circ}\end{array}$ & $1 / 2$ in. to $3 / 4$ in. dia. $2.25 \mathrm{MHz}, 45^{\circ}$ \\
\hline G & $1 / 4$ in. dia, $2.25 \mathrm{MHz}, 45^{\circ}$ & $1 / 2$ in. dia, $2.25 \mathrm{MHz}, 45^{\circ}$ \\
\hline $\mathrm{H}$ & $\begin{array}{l}1 / 4 \text { in. dia, or } 1 / 4 \times 1 / 4 \text { in., } \\
2.25 \mathrm{MHz}, 450^{\circ} \text { and } 60^{\circ}\end{array}$ & $1 / 2 \mathrm{in.} \times 1 / 2 \mathrm{in.}, 2.25 \mathrm{MHz}, 45^{\circ}$ and $60^{\circ}$ \\
\hline
\end{tabular}

$\begin{array}{cl}\text { What search units do you use for } \\ \text { Survey } & \text { ferritic pipe inspection? } \\ \text { Respondent } & \text { c) over 20-in. dia }\end{array}$

Are there special procedures for ferritic pipe?

\begin{tabular}{|c|c|c|}
\hline A & $1 / 2$ in. $x 1$ in., $2.25 \mathrm{MHz}, 45^{\circ}$ & none \\
\hline B & 1 in. $x 1 / 2$ in., $2.25 \mathrm{MHz}, 45^{\circ}$ & none \\
\hline C & -- & none \\
\hline 0 & -- & none \\
\hline $\mathrm{E}$ & $\begin{array}{l}1 / 2 \text { in. dia, } 1 / 2 \times 1 / 2 \text { in., or } 1 / 2 \times \\
1 \text { in., } 2.25 \mathrm{MHz}, 45^{\circ}\end{array}$ & none \\
\hline$F$ & $\begin{array}{l}3 / 4 \\
450\end{array}$ in. to 1 in. dia, $2.25 \mathrm{MHz}$, & none \\
\hline G & -- & none \\
\hline$H$ & $\begin{array}{l}1 / 2 \text { in. dia, } 1 \text { in, } x 1 / 2 \text { in. }(1.0 \\
\text { MHz permitted if lack of penetra- } \\
\text { tion noted) }\end{array}$ & none \\
\hline
\end{tabular}




\section{Inspection Practices for Ferritic and Stainless Steel Pipe (contd)}

Survey What confidence do you have in Respondent ferritic inspection?

A high

B $\quad 75 \%$ to $80 \%$

C high for fatigue cracks

D very high

E very nigh

F good, no problems

G good

H good
What search units do you use for austenitic stainless steel pipe? a) up to 10-in. dia

$1 / 4$ in. to $1 / 2 \mathrm{in.} \mathrm{dia,} 2.25 \mathrm{MHz}, 45^{\circ}$; generaily prefers smaller transducers somet imes $1 / 4 \mathrm{in} . \times 1 / 4 \mathrm{in}$. on smali pipe

$1 / 4 \mathrm{in.} \times 1 / 4$ in., $2.25 \mathrm{MHz}, 45^{\circ}$ (5.0 MHz used on $5 m a l l$ pipe)

1/2 in. dia, $2.25 \mathrm{MHz}, 45^{\circ}$

$3 / 8 \mathrm{in}$. to $1 / 2 \mathrm{in.,} 1.5 \mathrm{MHz}$

$1 / 4$ in. dia, $2.25 \mathrm{MHz}, 45^{\circ}$

$1 / 4$ in. dia, or $1 / 4 \times 1 / 4$ in., $2.25 \mathrm{MHz}, 45^{\circ}$ and $60^{\circ}$; for piping greater than 0.75 in. thick, a dual-element (1.5-MHz) search unit is used.

\begin{tabular}{|c|c|}
\hline $\begin{array}{l}\text { Survey } \\
\text { Respondent }\end{array}$ & $\begin{array}{l}\text { What search units do you use for } \\
\text { austenitic stainless steel pipe? } \\
\text { b) } 10 \text { - to } 20 \text {-in. dia. }\end{array}$ \\
\hline A & $\begin{array}{l}1 / 2 \text { in. dia or } 1 / 2 \text { in. } x 1 \text { in., } \\
2.25 \mathrm{MHz}, 450\end{array}$ \\
\hline B & $\begin{array}{l}\text { (don't use } 60^{\circ} \text { except for } \\
\text { evaluation) }\end{array}$ \\
\hline C & $1 / 2 \mathrm{in.} \mathrm{dia,} 2.25 \mathrm{MHz}, 45^{\circ}$ \\
\hline 0 & -- \\
\hline $\mathrm{E}$ & $\begin{array}{l}1 / 2 \text { in. dia, } 1.6 \mathrm{MHz} \text { as of } \\
1 / 1 / 78 \text { using dual units }(1.6 \mathrm{MHz})\end{array}$ \\
\hline $\mathrm{F}$ & $3 / 8 \mathrm{in}$. to $1 / 2 \mathrm{in}$ dia, $1.5 \mathrm{MHz}$ \\
\hline G & $1 / 2$ in. dia, $2.25 \mathrm{MHz}, 45^{\circ}$ \\
\hline $\mathrm{H}$ & $\begin{array}{l}1 / 2 \text { in. } x 1 / 2 \text { in., } 2.25 \mathrm{MHz}, \\
45^{\circ} \text { and } 60^{\circ} ; \text { for piping } \\
\text { greater than } 0.750 \text { in. thick, } \\
\text { a dual-element (1.5-MHz) search } \\
\text { unit is used. }\end{array}$ \\
\hline
\end{tabular}

c) over 20-in. dia.

$1 / 2$ in. $x 1$ in., $2.25 \mathrm{MHz}, 45^{\circ}$

1 in. $x 1 / 2$ in., $2.25 \mathrm{MHz}, 45^{\circ}$

1/2 in. dia, $2.25 \mathrm{MHz}, 45^{\circ}$

$1 / 2 \mathrm{in}$. dia, $1.6 \mathrm{MHz}$ as of $1 / 1 / 78$ using dual units $(1.6 \mathrm{MHz})$

$1 / 2$ in. $x 1$ in., $1 / 2$ in. $x 3 / 4$ in., $1.5 \mathrm{MHz}$

$1 / 2$ in. dia, 1 in. $x 1 / 2$ in. (1.0 $\mathrm{MHz}$ permitted if lack of penetration noted 


\section{Inspection Practices for Ferritic and Stainless Steel Pipe (contd)}

\begin{tabular}{|c|c|c|}
\hline $\begin{array}{c}\text { Survey } \\
\text { Respondent }\end{array}$ & $\begin{array}{l}\text { Have you used, evaluated, or considered } \\
\text { using a dual-element search unit? } \\
\text { What is your opinion of their usefulness? }\end{array}$ & $\begin{array}{l}\text { What do you use for an austenitic SS } \\
\text { stainless steel standard? } \\
\text { Any other calibration aide? }\end{array}$ \\
\hline A & $\begin{array}{l}\text { We have two dual-element search units } \\
\text { (1.5 } \mathrm{MHz} \text { ) and are considering using } \\
\text { them; they seem to work well for thin- } \\
\text { wall pipe inspections. }\end{array}$ & $\begin{array}{l}\text { ASME Section XI, Appendix III } \\
\text { standards }\end{array}$ \\
\hline$B$ & $\begin{array}{l}\text { We have used one; it does not make much } \\
\text { of an improvement. We used it on } \\
\text { centrifugally cast pipe. }\end{array}$ & pipe standard $5 \%$ notches \\
\hline C & $\begin{array}{l}\text { We use a dual line-focused search } \\
\text { unit for geometry, We are looking at } \\
\text { IGSCC applications for this search unit. }\end{array}$ & $\begin{array}{l}\text { Pipe standard has } 10 \text { and } 00 \text { notches. } \\
\text { We also use IGSCC samples. }\end{array}$ \\
\hline 0 & $\begin{array}{l}\text { Sometimes a dual-element search unit is } \\
\text { used; it has a better signal-to-noise. } \\
\text { characteristic. }\end{array}$ & $\begin{array}{l}\text { ASME Section XI, Appendix III } \\
\text { standards }\end{array}$ \\
\hline$E$ & We are using dual-element units. & pipe standard $5 \%$ notch \\
\hline $\mathrm{F}$ & $\begin{array}{l}\text { We have looked at them but have none in } \\
\text { general use. They were used on a control } \\
\text { rod drive inspection. Selection of } 1.5 \\
\text { MHz was the result of an EPRI program. (a) } \\
\text { We may use them in the future. }\end{array}$ & $\begin{array}{l}\text { ASME Section XI, Appendix III } \\
\text { standards }\end{array}$ \\
\hline G & Yes. They have shown good performance. & $\begin{array}{l}\text { ASME Section XI, Appendix III } \\
\text { standards }\end{array}$ \\
\hline $\mathrm{H}$ & $\begin{array}{l}\text { Yes, but they have only been looked at } \\
\text { in the lab, not for field service yet. } \\
\text { There is no move to use them. }\end{array}$ & $\begin{array}{l}\text { ASHE Section XI, Appendix III } \\
\text { standards }\end{array}$ \\
\hline
\end{tabular}

(a) Reinhart, E. R. 1979. Horkshop On In-Service Inspection of Stainless Steel Piping in Nuclear Systems. Electric Power Research Inst itute Project 892, Palo Alto, California. 


\section{Inspection Practices for Ferritic and Stainless Steel Pipe (contd)}

\begin{tabular}{|c|c|c|}
\hline $\begin{array}{c}\text { Survey } \\
\text { Respondent }\end{array}$ & $\begin{array}{l}\text { Austenitic stainless steel special } \\
\text { procedure, skew, recording level, scan } \\
\text { pattern, etc.? }\end{array}$ & $\begin{array}{l}\text { What conf idence do you have in austenitic } \\
\text { stainless steel pipe inspect ion? } \\
\text { d) For flaws } 10 \% \text { to } 25 \% \text { of wall thick- } \\
\text { ness (T) in depth. }\end{array}$ \\
\hline A & none & $80 \%$ at $25 \% \mathrm{~T}$; borderline at $10 \% \mathrm{~T}$ \\
\hline B & no, same as ASME Section $V$ & $85 \%$ \\
\hline c & $\begin{array}{l}\text { special procedure and training of } \\
\text { personnel for extreme skew; lower } \\
\text { recording level; procedyre close to } \\
\text { EPRI workshop procedure (d) }\end{array}$ & reliably detect IGSCC at 50\% $\mathrm{T}$ \\
\hline D & none & - \\
\hline $\mathrm{E}$ & $\begin{array}{l}\text { We record anything over } 20 \% \text { DAC. The } \\
\text { procedure is close to the EPRI work- } \\
\text { shop procedure. (a) }\end{array}$ & $50 \%$ \\
\hline $\mathrm{F}$ & We record anything at or over $50 \% \mathrm{DAC}$ & 606 to 706 \\
\hline G & $\begin{array}{l}\text { Special procedures are used only if } \\
\text { looking for IGSCC; then the skew is } \\
\text { greater. We used a dual-element } \\
\text { transducer. }\end{array}$ & $70 \%$ \\
\hline $\begin{array}{c}\text { Survey } \\
\text { Respondent }\end{array}$ & $\begin{array}{l}\text { What confidence do you have in } \\
\text { austenitic stainless steel pipe } \\
\text { inspection? } \\
\text { b) at } 25 \% \text { to } 50 \% \text { I? }\end{array}$ & c) at over $50 \% \mathrm{~T}$ ? \\
\hline A & $100 \%$ & $100 \%$ \\
\hline B & $100 \%$ & $100 x$ \\
\hline c & $100 \%$ & $100 \%$ \\
\hline D & $-*$ & -- \\
\hline$E$ & $75 \%$ & $75 x$ \\
\hline $\mathrm{F}$ & $80 x$ & $90 x$ to $100 \%$ \\
\hline G & $90 \%$ & $95 \%$ \\
\hline$H$ & $100 \%$ & $100 \%$ \\
\hline$H$ & $70 \%$ & \\
\hline
\end{tabular}

(a) Reinhart, E. R. 1979. Workshop On In-Service Inspection of Stainless Steel Piping in Nuclear Systems. Electric Power Research Institute Project 892, Palo Alto, California. 


\title{
4. Inspection Practices for Ferritic and Stainless Steel Pipe (contd)
}

\author{
Survey \\ Respondent \\ Coments on inspection experience with austentic stainless steel \\ A Most indications are 25\% amplitude and over. Inspection performance \\ improved due to round robin sponsored by EPRI. We now place less \\ emphasis on signal amplitude and take more time to perform a detailed \\ inspection. \\ B \\ no IGSCC on major piping sections \\ c \\ Our approach for IGSCC is to look at high-stress components with \\ conventional techniques at $2.25 \mathrm{MHz}$. No geometric calls are allowed for \\ piping that is susceptible to stress corrosion. One should consider an \\ ISI program based on critical components and high-stress welds. Sutar \\ instrumentation should help time and exposure problems; one approach we \\ have used to reduce personnel exposure is to drain and flush the lines to \\ be tested, if possible. This seems to save substantial time for \\ radiography and ultrasonic testing of the weld by reducing radiation \\ exposure. \\ D Data must be automatically recorded. \\ E Current inspection technique is good. Need another workshop. Need more \\ IGSCC samples available with smaller cracks. \\ F It is our experience that there has been only one leaker that ISI did not \\ find first. \\ G limited experience with IGSCC \\ H Performance depends on highly skilled operator and training for special \\ problems like IGSCC.
}




\section{Experience with Centrifugally Cast Stainless Steel}

Survey Have you inspected centrifugally Respondent cast pipe?

A yes

B yes

C $\quad--$

$0 \quad$ yes

E yes

What search units and inspection

Survey

Respondent

A $1 / 2$ in. dia

B dual unit

c $\quad 1$ in. dia

o 1 in. dia

E $\quad 1 / 2 \mathrm{in.}$ dia, $(1.5 \mathrm{MHz})$

$1 / 2$ in. $x 1$ in. $(2.25 \mathrm{MHz})$

Survey

Respondent What instrument was used?

A Sonic $\mathrm{MK}-\mathrm{l}$

B Sonic $M K-1$

C $\quad K B \cup S M-2$

D $\quad--$

E Sperry UJ
What search units and inspection conditions were used? a) frequency

$1 \mathrm{MHz}$

$1.5 \mathrm{MHz}$

$1.5 \mathrm{MHz}$

$1.0 \mathrm{MHz}$

$1.5 \mathrm{MHz}, 2.25 \mathrm{MHz}$

c) longitudinal (L) or shear

$45^{\circ}$, shear; also some refracted L-wave

$45^{\circ}$, refracted L-wave

$40^{\circ}$, refracted L-wave

$45^{\circ}$, refracted L-wave

$45^{\circ}$, refracted L-wave

Are there special procedures or evaluation techniques?

Nothing yet; we are studying

the problem.

no

yes

We did use special preamp at one time, but this practice was recent ly dropped.

no 


\section{Experience with Centrifugally Cast Stainless Steel (contd)}

\begin{tabular}{|c|c|c|}
\hline $\begin{array}{c}\text { Survey } \\
\text { Respondent }\end{array}$ & $\begin{array}{l}\text { What confidence do you have in } \\
\text { inspection of centrifugally cast pipe? }\end{array}$ & What type of standard was used? \\
\hline A & Inspection is difficult. & + \\
\hline B & not very confident & pipe section ith $5 \% \mathrm{~T}$ notches \\
\hline C & pretty good confidence & $\begin{array}{l}\text { We started with a welded pipe } \\
\text { standard but went to a base } \\
\text { metal standard since the base } \\
\text { metal is more attenuative. }\end{array}$ \\
\hline 0 & $\begin{array}{l}\text { Good to fair; we can see code-size } \\
\text { reflectors; however, there are many } \\
\text { metallurgical reflectors. }\end{array}$ & $\begin{array}{l}\text { Side-drilled holes in centri- } \\
\text { fugally cast parts were used; } \\
\text { cracked specimens are needed. }\end{array}$ \\
\hline$E$ & $\begin{array}{l}20 \% \text { confidence in the } 1.5-M H z \\
\text { inspection; no confidence in the } \\
2.25-\mathrm{MHz} \text { inspection }\end{array}$ & $\begin{array}{l}\text { Side-drilled holes and an IO } \\
\text { notch were used. At one plant } \\
\text { we could not detect the notch } \\
\text { in the standard; likewise at } \\
\text { another plant we could not } \\
\text { detect either the notch or } \\
\text { side-drilled holes. }\end{array}$ \\
\hline
\end{tabular}




\section{Automated Inspection Practices}

Survey Do you perform automated

Respondent pipe weld inspection?

A

B

C

D

$E$

$\mathrm{F}$

$\mathrm{H}$

Survey

Respondent

A

B

C

0

E

$\mathrm{F}$

G

$\mathrm{H}$
$--$

$--$

No, we have not seen the

need yet, but we may have

to in the future, because

of radiation levels.

Yes, only from the nozzle

to safe end, and safe end to

pipe; we have done base-

line inspections using

automated equipment but

no ISI.

Yès, only from the nozzle to safe end and safe end to pipe.

Yes, only from the nozzle to safe end and safe end to pipe.

no

no

Equipment description

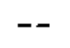

$--$

$-$

trace-type scanner

pipe weld inspection "bug," track chain, etc.
Approximately what percentage does automated testing represent?

$25 \%$

$5 \%$

$0 \%$

$2 \%$

Access Requirement

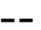

8-in. annular clearance around pipe

18 in. either side of weld 


\section{Automated Inspection Practices (contd)}

Survey

Respondent Crown height requirement

A

$B$

C

D $1 / 32$ in.

E flush or smooth taper

F $\quad--$

G $\quad--$

H Flush is best; flat would be the manual or strip chart minimum.
Data recording equipment

minicomputer; magnetic tape

strip chart, analog tape, and videotape; data is played back $100 \%$ and reviewed.

--

$\rightarrow$

Survey

Respondent Do you use static or dynamic calibration?

$\begin{array}{ll}\text { A } & -- \\ \text { B } & -- \\ \text { C } & -- \\ \text { D } & \text { static } \\ \text { E } & \text { statiC } \\ \text { F } & -- \\ \text { G } & -- \\ \text { H } & \text { static }\end{array}$

A. 20 


\section{Automated Inspection Practices (contd)}

Survey What coupling method is used Respondent and how is coupling ver if ied?

A

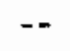

B

C $\quad-$

D water, --

E water, --

F $\quad--$

G $\quad-$

H water with ethylene glycol; 0 monitor for couplant verification
What is your opinion of the relative merits of manual versus automated testing?

Manual is superior; designs of automatic equipment are poor, and they will never replace manual scan by an experienced operator. For critical problems we use manual over automated systems every time. Automated inspection is too complicated, too time consuming.

Manual inspection takes about the same time as automated inspection. Automated inspection takes too much time to set up.

No difference in relative merit; manual inspection is more versatile but suffers in repeatability.

Manual inspection with experienced people is better. Automated systems are "unproven."

Manual is better but automated inspection results in lower personnel radiation exposure.

$+$

$-\cdot$

Automated inspection is effective for certain inspections such as the safe-ends. 
7. Pipe Outer Diameter Geometry Conditions

Survey What percent of Class I welds have

Respondent single-side access?

$\begin{array}{llll}\text { A } & -- & \text { unknown } & \sim 10 \% \\ \text { B } & -- & 10 \% & 15 \% \\ \text { C } & -- & \sim 90 \% & \sim 60 \text { to } 70 \% \\ \text { D } & -- & \sim 10 \% & \sim 10 \% \\ \text { E } & -- & 10 \% & 10 \% \\ \text { F } & -- & 10 \% \text { to } 20 \% & 10 \% \text { to } 20 \% \\ \text { G } & -- & 10 \% & -- \\ \text { H } & -- & -- & 15 \% \\ \text { I } & 20 \% & -- & -- \\ \text { J } & 100 \% & -- & --\end{array}$

Survey What special test procedures and evaluation

Respondent criteria are used for single-sided access?

A L-wave inspection at top of weld; only shoot through weld if there is a reportable indication; usualiy uses $45^{\circ}$

B include calibration L-wave on one side; sometimes change shear inspection angles

C Always try to get $1 / 2 \mathrm{~V}$ exam. If weld crown is a problem, the crown is ground.

D none

E no special procedure

F none; use $3 / 2 \vee$ through weld

G none; use $3 / 2 \vee$ through weld

$\mathrm{H} \quad$ none

I none

J No special procedure or evaluation criteria exist for austentic welds. All austentic welds are ground for $1 / 2 \mathrm{~V}$ access. 


\section{Pipe Outer Diameter Geometry Conditions (contd)}

Survey Is the most attentuative material used for a standard?

Respondent If not, is it available?

A Standards are made from the same material used in the plant

piping. If available, the most attenuative material will be used.

B No attentuation measurements are made.

C No; for example, cast valve material is difficult to obtain.

D Standards are presumed to be from typical material.

E We use what the plant supplies.

F No; there is no good method of taking attentuation measurements.

G yes; particularly with bimetallic welds such as Inconel to carbon stee?

H Inconel

I No; standards are certainiy variable. Standards could vary as much as $3 \mathrm{~dB}$ especialiy in the bimetaliic and trimetallic standards.

$-$

Survey

What percent of weld crowns are ground for PWR primary coolant pipe welds?

Respondent \% flush onot ground

$\%$ ground flat not flush

A $\quad 100 \%$

$0 \%$

$0 \%$

B $\quad 0 \%$

$0 \%$

$100 \%$

C --

--

$\sim 90 \%$

D

(a)

E

(b)

F $\quad 40 \%$

$10 \%$

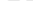

G $\quad 100 \%$

$0 \%$

$50 \%$

H

I

(a) It depends on the age of the plant. New plants coming on-line have welds biended. Older plants have welds ground flat.

(b) All Class I primary and ma in coolant welds are grounds flush or flat. 
7. Pipe Outer Diameter Geometry Conditions (contd)

What percent of weld crowns are ground for BWR main coolant Survey pipe welds?

Respondent \% flush \% \%ot ground ground flat not flush

$\begin{array}{llll}\text { A } & 0 \% & 0 \% & 100 \% \\ \text { B } & 0 \% & 0 \% & 100 \% \\ \text { C } & -- & \sim 10 \% & \sim 80 \% \\ \text { D } & -- & -- & -- \\ \text { E } & -- & -- & -- \\ \text { F } & 20 \% & 20 \% & 60 \% \\ \text { G } & -- & -- & -- \\ \text { H } & 100 \% \text { after } 1977 & 90 \% \text { prior to } 1977 & -- \\ \text { I } & 10 \% & 10 \% \text { p } & 80 \%\end{array}$

\footnotetext{
Survey What, if any, compensating procedures are

Respondent used for severe diametrical shrinkage?

A none

B none

C We have used a TIG filler wash weld for shrinkage problems.

D $\quad--$

E none encountered

$F \quad$ If search unit tilts, use profile gauge to measure angle for plotting of data.

G none

H none

I This problem has occurred in thin-wall pipe; no special procedures used.
} 


7. Pipe Outer Diameter Geometry Conditions (contd)
$\begin{array}{cl}\begin{array}{c}\text { Survey } \\ \text { Respondent }\end{array} & \text { What are typical surface finishes? } \\ \text { A } & \sim 125 \mathrm{rms} \\ \text { B } & \sim 250 \mathrm{rms} \\ \text { C } & 250 \mathrm{rms} \\ \text { D } & 125 \mathrm{rms} \\ \text { E } & 125 \mathrm{rms} \\ \text { F } & 250 \mathrm{rms} \\ \text { G } & 250 \mathrm{rms} \\ \text { H } & 250 \mathrm{rms} \\ \text { I } & 125 \mathrm{rms}\end{array}$




\section{Pipe Inner Diameter Geometry Conditions}

\begin{tabular}{|c|c|}
\hline $\begin{array}{c}\text { Survey } \\
\text { Respondent } \\
\end{array}$ & $\begin{array}{l}\text { How we } 11 \text { can the shape of the } \\
\text { counterbore (C.B.) be measured? }\end{array}$ \\
\hline A & $\begin{array}{l}\text { Given enough time, a fairly } \\
\text { good job can be done. However, } \\
\text { during normal inspect ion "you } \\
\text { just make a quick judgement." }\end{array}$ \\
\hline$B$ & $\begin{array}{l}\text { Not very we } 11 \text {; normal beam } \\
\text { inspection is used to see how } \\
\text { the back wall changes. }\end{array}$ \\
\hline C & $\begin{array}{l}\text { We use a line-focused dual } \\
\text { unit for thickness profile. } \\
\text { occasionally we call for a } \\
\text { radiography (tangent shot). }\end{array}$ \\
\hline D & -- \\
\hline$E$ & not very \\
\hline
\end{tabular}

$F \quad$ Normal-beam inspection is used to profile the C.B. Radiographs are taken when possible.

G

$\mathrm{H}$ not very we 11

I Very poorly; you can only measure wall thickness and usually determine where the C.B. changes.

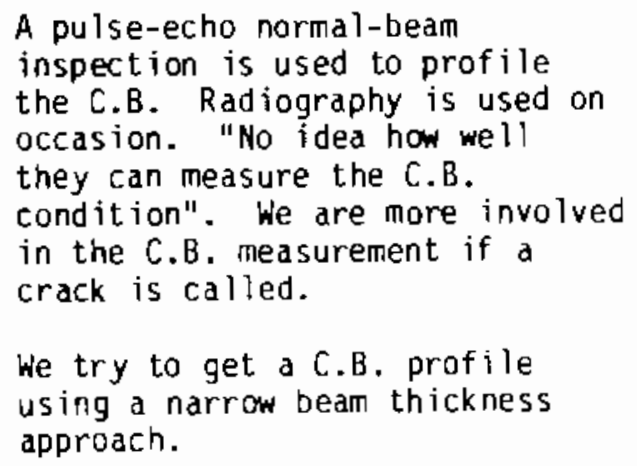

How often is as-built information on counterbore available? Is this baseline informaton?

Usually some record can be found; however, many times it is anbiguous since optional ways of fabrication are allowed. No baseline ultrasonic inspection of the C.B. Condition is made.

Although design specifications are available, there are no as-built C.B. drawings.

There is no information on current operating units other than radiographs.

Seldom is there any as-built or baseline information.

oid plants never have this information. Sometimes even radiographs are unavailable. Generally baseline information is not recorded.

Design specifications are used all the time.

A generalized drawing is usually available at most piants. This is not baseline information.

Very seldom; this is not baseline information.

occasionally
Sometimes as-built information is used; C.B. radiography is sometimes used to determine shape. 


\section{Pipe Inner Diameter Geometry Conditions (contd)}

Survey How often is baseline information on geometric Respondent reflectors available?

A $\quad 50 \%$

B Most of the time we can get geometric reflector baseline information recorded at $20 \%$ DAC.

C We are concerned with suck up and counterbore inductions.

D Baseline data is usually limited to measurement of a few spots. Depending on the situation, it may be very helpful.

E Geometric reflector baseline data is sometimes available but can be difficult to use; e.g., prior reference or metal path is sometimes undefined.

$F \quad$ Baseline information is available 30 to $40 \%$ of the time; sometimes baseline information is not supplied when requested.

$G$ Correct information is frequently available.

H not very often

I $\quad \cdots$

J Sometimes geometric indications are reported, somet imes not; reporting of geometric indications would save Level II and Level III time. If they are not reported on the data sheet but are noted by plant inspection personne?, follow-on inspections can be a check on the contracting inspection agency. Experience with a lot of drop-through is reported.
Is this geometric reflector information correct?

If recorded, it is pretty accurate.

Yes, it is recorded on strip chart

Information is generally correct. Some signal indications which were called geometric reflectors have actually turned out to be stress corrosion cracking. 


\section{Pipe Inner Diameter Geometry Conditions (contd)}

\begin{tabular}{|c|c|c|}
\hline $\begin{array}{c}\text { Survey } \\
\text { Respondent }\end{array}$ & $\begin{array}{l}\text { If the baseline inspection is performed by } \\
\text { different organizations, of what value is it? }\end{array}$ & What are the difficulties? \\
\hline A & $\begin{array}{l}\text { All information is of value; past baselines } \\
\text { have not been too good but baselines have } \\
\text { improved in the last two years. }\end{array}$ & $\begin{array}{l}\text { Location is difficult since pipes } \\
\text { have no reference points. }\end{array}$ \\
\hline B & $\begin{array}{l}\text { Baselines should be valid if procedures and } \\
\text { calibration blocks are the same. }\end{array}$ & no major problems \\
\hline$C$ & -- & -- \\
\hline 0 & -- & $\begin{array}{l}\text { Sumarizing these complex responses } \\
\text { in a few words is difficult. }\end{array}$ \\
\hline$E$ & -- & -- \\
\hline$F$ & - & -. \\
\hline G & $\begin{array}{l}\text { We do not record geometry; therefore, } \\
\text { baseline inspection is lacking this informa- } \\
\text { tion. }\end{array}$ & -- \\
\hline $\mathrm{H}$ & $\begin{array}{l}\text { Baseline data is often of very little value, } \\
\text { since procedure (or lack of it) and levels } \\
\text { of recording can be different. }\end{array}$ & -- \\
\hline I & $-\infty$ & $\begin{array}{l}\text { One difficulty is when the geometry } \\
\text { condition is determined from UT but } \\
\text { not recorded. }\end{array}$ \\
\hline 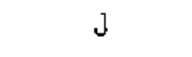 & -- & -- \\
\hline K & -- & -- \\
\hline
\end{tabular}




\section{Pipe Inner Diameter Geometry Conditions (contd)}

\begin{tabular}{|c|c|c|}
\hline $\begin{array}{c}\text { Survey } \\
\text { Respondent } \\
\end{array}$ & $\begin{array}{l}\text { Is a standard format for recording geometric } \\
\text { indications needed? Should this be a Code } \\
\text { requirement?. Or regulatory requirement? }\end{array}$ & $\begin{array}{l}\text { How do you evaluate } 3 / 2 V \text { indications } \\
\text { when the beam is incident on the } \\
\text { conical section of the counterbore? }\end{array}$ \\
\hline A & yes, no, no & $\begin{array}{l}\text { With finger damping on surface and } \\
\text { normal-beam to profile the } C . B \text {. ; mode } \\
\text { conversion is not calculated. Sound } \\
\text { path is plotted. }\end{array}$ \\
\hline B & yes, no, no & $\begin{array}{l}\text { Look at RT film; look with UT at both } \\
\text { sides; finger damp; look at design } \\
\text { specs; plot sound path on x-section; } \\
\text { don't usually consider ref. wave. }\end{array}$ \\
\hline c & yes, yes, no & $\begin{array}{l}\text { We try to get a } 1 / 2 \vee \text { exam; if there } \\
\text { are problems, the crown is removed. }\end{array}$ \\
\hline D & $\begin{array}{l}\text { All tests should be recorded on strip } \\
\text { chart. This should be a requirement for } \\
\text { any examination repeated periodically. }\end{array}$ & $\begin{array}{l}\text { All indications are evaluated on a } \\
\text { case-by-case basis. }\end{array}$ \\
\hline$E$ & $\begin{array}{l}\text { A standard format is needed, and a Code } \\
\text { comittee should do this. Even in-house } \\
\text { formats change from year to year. }\end{array}$ & $\begin{array}{l}\text { We request that welds be flush. If } \\
\text { there are indications, we use finger } \\
\text { damping. }\end{array}$ \\
\hline$F$ & $\begin{array}{l}\text { Geometry indications are described on } \\
\text { ISI data sheets. }\end{array}$ & $\begin{array}{l}\text { We haven't had that problem with } \\
\text { primary pipe. Two-side access for } \\
1 / 2 V \text { and } V \text { exams has been possible. }\end{array}$ \\
\hline$G$ & $\begin{array}{l}\text { No; Code already says you shail record } \\
\text { defect-like indications. }\end{array}$ & $\begin{array}{l}\text { With great difficulty; hopefully the } \\
\text { C.B. angle is known; finger damping. }\end{array}$ \\
\hline$H$ & $\begin{array}{l}\text { A standard format is needed and we use one. } \\
\text { It should be a Code requirement. }\end{array}$ & -- \\
\hline I & yes, yes, no & $3 / 2 V$ information is not used. \\
\hline$J$ & $\begin{array}{l}\text { No; geometry indications are reported } \\
\text { on ISI data sheet. }\end{array}$ & $\begin{array}{l}\text { A } 1 / 2 V \text { exam is used for most cases; } \\
\text { for } 3 / 2 V \text { exam nothing special is } \\
\text { done. }\end{array}$ \\
\hline$k$ & $\begin{array}{l}\text { No, geometric indications can be plotted } \\
\text { out on ISI data sheet. }\end{array}$ & $\begin{array}{l}\text { We request that all welds are } \\
\text { ground flat to allow a } 1 / 2 \mathrm{~V} \text { exam. }\end{array}$ \\
\hline
\end{tabular}




\section{Calibration, Inspection, and Flaw Evaluation}

\begin{tabular}{|c|c|c|}
\hline $\begin{array}{l}\text { Survey } \\
\text { espondent }\end{array}$ & $\begin{array}{l}\text { Calibration and Inspection } \\
\text { a) When do you verify calibration? }\end{array}$ & $\begin{array}{l}\text { b) What transducer scan overlap } \\
\text { do you use? }\end{array}$ \\
\hline A & $\begin{array}{l}\text { Recalibrate every } 4 \text { hours, and/or at } \\
\text { change of operators. }\end{array}$ & $10 \%$ \\
\hline B & $\begin{array}{l}\text { Recalibrate every } 4 \text { hours, and/or at } \\
\text { change in operators or equipment. }\end{array}$ & $10 \%$ \\
\hline C & $\begin{array}{l}\text { Recalibrate every } 4 \text { hours and/or at change } \\
\text { of operators. }\end{array}$ & $10 \%$ to $20 \%$ \\
\hline$D$ & $\begin{array}{l}\text { Recalibrate before and after each component } \\
\text { examination. }\end{array}$ & $15 \%$ \\
\hline$E$ & $\begin{array}{l}\text { Recalibrate every } 4 \text { hours and/or at opera- } \\
\text { tor change. }\end{array}$ & $25 \%$ \\
\hline$F$ & $\begin{array}{l}\text { Recalibrate every } 4 \text { hours or at operator } \\
\text { change. }\end{array}$ & $10 \%$ \\
\hline G & $\begin{array}{l}\text { Recalibrate every } 4 \text { hours and at the end of } \\
\text { inspection. }\end{array}$ & $10 \%$ \\
\hline$H$ & $\begin{array}{l}\text { Recalibrate every } 4 \text { hours, or when } \\
\text { operator is changed. }\end{array}$ & $10 \%$ \\
\hline I & Recalibrate every 4 hours. & $20 \%$ manual; $10 \%$ automatic \\
\hline
\end{tabular}




\section{Calibration, Inspection, and Flaw Evaluation (contd)}

Calibration and Inspection
Survey
Respondent Is transducer skew used during the scan?
How much? Is it mandatory or recommended?

A Yes; $20^{\circ}$; this is not mandatory or recommended, but it is practiced.

B Yes; the amount of skew is not specified, but the use of some skew is our recommended practice.

C Yes, 20; skew is not mandatory or recommended but it is practiced.

0

E yes; $15^{\circ}$ to $20^{\circ}$ normally; $45^{\circ}$ for IGSCC

F no skew

G Yes; up to $15^{\circ}$; the skew angle is recorded if important to define indication position. This practice is taught but is not a written procedure; however, it is practiced to achieve maximum signal amplitude by search unit manipulation.

$\mathrm{H}$ yes, if looking for IGSCC, but this is not in written procedure.

1 Yes, up to $45^{\circ}$; the amount of skew is dependent on the operator.
Flaw Evaluation

a) What is the data recording procedure?

Procedure calls for recording down to $20 \%$ of maximum indicated amplitude.

Note indications at $20 \%$ of $D A C$; record and evaluate at $50 \%$ of $O A C$.

Record at $50 \%$ of DAC;

investigate at $20 \%$ of DAC.

Signal amplitude and range are recorded on strip charts continuously.

Use Code Section XI criteria.

Investigate at $25 \%$ of DAC; record at $50 \%$ of DAC; evaluate at $100 \%$ of DAC.

Standard record sheet is used; amplitude $(+6 \mathrm{~dB}$ down) metal path, two-dimensional position.

Record at 50\% DAC; evaluate at $100 \%$ of DAC.

Use Code Section XI criteria. 


\section{Calibration, Inspection, and Flaw Evaluation (contd)}

\begin{tabular}{|c|c|}
\hline $\begin{array}{l}\text { Survey } \\
\text { espondent }\end{array}$ & $\begin{array}{l}\text { Flaw Evaluation } \\
\text { b) What is the position accuracy on } \\
\text { the pipe surface? }\end{array}$ \\
\hline A & \pm 0.050 in.; ruler accuracy \\
\hline$B$ & $\pm 0.20 \mathrm{in}$. \\
\hline c & ruler accuracy \\
\hline 0 & $\begin{array}{l}\text { manual measurement to we lo edge or } \\
\text { reference line: } 1 / 8 \mathrm{in.}\end{array}$ \\
\hline E & $0.125 \mathrm{in.}$ \\
\hline $\mathrm{F}$ & ruler accuracy \\
\hline G & 0.10 to $0.125 \mathrm{in}$. \\
\hline H & \pm 0.10 to $0.20 \mathrm{in}$. \\
\hline I & $0.06 \mathrm{in}$. \\
\hline
\end{tabular}

c) What are the time metal path accuracies for $1 / 2 \vee$ and $3 / 2 \vee$ exams?

\pm 0.10 for $1 / 2 \vee$ exam; drops considerably on for $3 / 2 \vee$ exam

+0.010 for $1 / 2 \quad V$ exam; guess +0.020 for $\overline{3} / 2 \vee$ exam

good to within one minor division on scope; check with thickness gage

Digital readout is usually within $+0.10 \mathrm{in.}$ +0.06 in. $1 / 2 \mathrm{~V}$ exam; within 0.38 in. for $3 / 2 \vee$ exam

$\rightarrow$

$+0.125 \mathrm{in}$. for both $1 / 2 \mathrm{~V}$ and $3 / 2 \mathrm{~V}$ exam

+0.10 in. for $1 / 2 \vee$ exam; 0.20 in. for $\overline{3} / 2 \vee$ due to beamspread

$0.05 \mathrm{in}$. for $1 / 2 \vee$ exam; 0.075 to $0.10 \mathrm{in}$. for $3 / 2 \vee$ exam, but $3 / 2 \vee$ exam is not normally used. 


\section{Calibration, Inspection, and Flaw Evaluation (contd)}

Survey Flow Evaluation

Respondent d) Do you use supplementa] tests?

$\begin{array}{ll}\text { A } & \text { yes } \\ \text { B } & \text { yes } \\ \text { C } & \text { yes; RT, PT, UT } \\ \text { D } & \text { yes } \\ \text { E } & \text { yes; RT, MT, grinding } \\ \text { F } & -- \\ \text { G } & \text { yes } \\ \text { H } & -- \\ \text { I } & \begin{array}{l}\text { not usually; maybe PT, but not } \\ \text { usully RT }\end{array}\end{array}$

d1) Other angles, frequencies

$60^{\circ}$; higher frequency on L-wave

$35^{\circ}$ to $70^{\circ}$ at 2.25 to $5 \mathrm{MHz}$; hardiy ever $1.0-\mathrm{MHz}$ exam except for centrifugally cast pipe

$60^{\circ}$ and $70^{\circ}$ at $2.25 \mathrm{MHz}$ and higher frequency exam; full $V$ with finger damping if no $1 / 2 V$ access

$60^{\circ}$ and $70^{\circ}$ at $5 \mathrm{MHz}$; use of dualelement unit

$60^{\circ}$ and $70^{\circ}$ exam; for single-side access we like to use a $70^{\circ}$ exam; dual unit at $5 \mathrm{MHz}$ used for normal profile

$45^{\circ}, 60^{\circ}$, and $0^{\circ}$ on ly; $60^{\circ}$ for limited access; only use $2.25-\mathrm{MHz}$ frequency

yes, different size transducers

$45^{\circ}, 60^{\circ}$, and $70^{\circ} ; 1.0$ to $2.25 \mathrm{MHz}$ 


\section{Calibration, Inspection, and Flaw Evaluation (contd)}

Survey Flaw Evaluation

Respondent d2) Two-side evaluation

A yes

B yes

C - -

D yes, where possible

E yes

F yes, where possible

G yes

H yes

I yes, where possible

Survey What methods do you use to call Respondent ID geometry?

C

D

$\varepsilon$

$\mathrm{F}$

G

H

I $360^{\circ}$ signal indication, reference normal beam shot of counterbore

plotting technique-position from weld root

signal location, length, shape

plotting technique

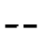

plotting technique - position from weld root (close to root, IGSCC) use refracted angle conversion chart to determine mode conversion plotting technique

plotting technique

plotting technique d3) Finger damping

yes

yes

yes

yes

yes

yes

yes

yes

yes

What methods to you use to call oD geometry?

finger damping

finger damping

$-$

signal location, length, shape grinding, finger damping, MT, PT

finger damping

plotting technique, finger dampening

finger damping 


\section{Calibration, Inspection, and Flaw Evaluation (contd)}

\begin{tabular}{|c|c|c|}
\hline $\begin{array}{c}\text { Survey } \\
\text { Respondent }\end{array}$ & When do you call for radiography? & When do you call for penetrant? \\
\hline A & $\begin{array}{l}\text { always when an indication is called } \\
\text { a cracked, or UT does not resolve } \\
\text { indication }\end{array}$ & $\begin{array}{l}\text { when UT indicates a large surface } \\
\text { or near-surface flaw }\end{array}$ \\
\hline B & $\begin{array}{l}\text { when UT cannot be resolved and } \\
\text { original RT is judged insufficient }\end{array}$ & $\begin{array}{l}\text { not usualiy; only when the operator } \\
\text { cannot get a complete scan in both } \\
\text { directions }\end{array}$ \\
\hline C & $\begin{array}{l}\text { if a suspect indication is found, } \\
\text { and after review of all prior } \\
\text { radiographs }\end{array}$ & when needed for 00 reflectors \\
\hline 0 & $\begin{array}{l}\text { only if prior radiographs are on } \\
\text { file }\end{array}$ & $\begin{array}{l}\text { when looking for small surface flaws; } \\
\text { i.e., plating cracks }\end{array}$ \\
\hline $\mathrm{E}$ & $\begin{array}{l}\text { After UT indicates a defect is } \\
\text { present; RT is used to confirm } \\
\text { the defect indication. }\end{array}$ & $\cdots$ \\
\hline $\mathrm{F}$ & $\begin{array}{l}\text { Utilities will request RT when } \\
\text { they feel UT is not adequate. }\end{array}$ & $\begin{array}{l}\text { Utility will call for penetrant } \\
\text { when needed. }\end{array}$ \\
\hline G & $\begin{array}{l}\text { "When I have made up my mind that } \\
\text { it is IGSCC"; RT may show weld } \\
\text { spatter and somet imes IGSCC }\end{array}$ & $\begin{array}{l}\text { when you suspect } 00 \text { cracking and always } \\
\text { after you have cut out a suspect pipe } \\
\text { section }\end{array}$ \\
\hline H & $\begin{array}{l}\text { when there are too many UT } \\
\text { signals to interpret or check } \\
\text { geometry }\end{array}$ & $\begin{array}{l}\text { when UT data indicates surface or } \\
\text { near-surface flaw }\end{array}$ \\
\hline I & $\begin{array}{l}\text { When one cannot make decision } \\
\text { based on the UT results, RT is } \\
\text { usually not called for during ISI. }\end{array}$ & when UT indicates a through-wall crack \\
\hline
\end{tabular}




\section{Calibration, Inspection, and Flaw Evaluation (contd)}

Survey

Respondent

\begin{tabular}{|c|c|}
\hline A & very of ten \\
\hline B & $3 \%$ to $5 \%$ \\
\hline c & on occasion \\
\hline D & seldorn \\
\hline$E$ & $\begin{array}{l}\text { about one per week during preservice } \\
\text { inspection to confirm geometry; about } \\
\text { l or } 2 \text { times per year for inservice } \\
\text { inspection }\end{array}$ \\
\hline$F$ & -- \\
\hline G & $\begin{array}{l}\text { every time IGSCC is indicated, about } \\
\text { once every site }\end{array}$ \\
\hline $\mathrm{H}$ & $5 \%$ \\
\hline I & seldom \\
\hline
\end{tabular}

How useful is radiography?

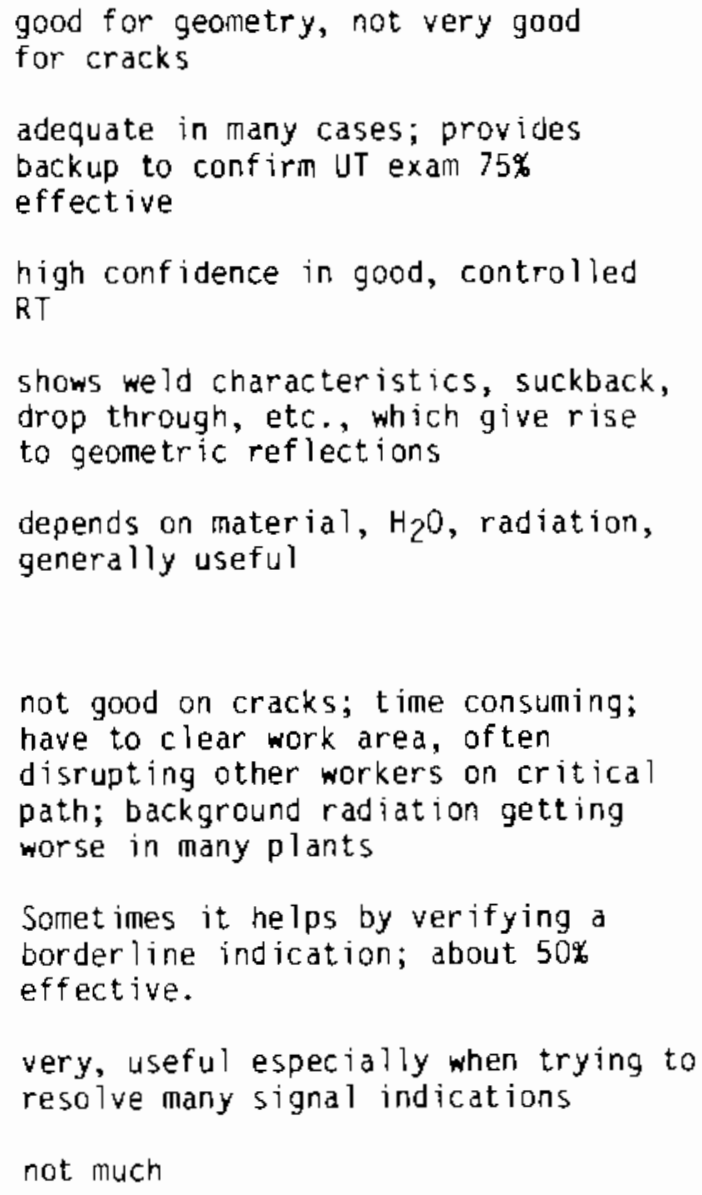




\section{Calibration, Inspection, and Flaw Evaluation (contd)}

Survey

Respondent What supplemental information do you call for?

A

drawings, design specifications, etc., to

eliminate one or more variables

B RT records, welding procedure, weld spec ifications and configuration

C

D weld preparation drawings

E ASME Section III radiographs, preservice records, and ISI records

F drawings or previous UT exam data

G preservice inspection and previous ISIs

$\mathrm{H}$ contour gauge measurements, as builts, preservice inspection information, weld preparation details

I preservice inspection, ISI, and as-built drawings (Early reactors have very poor records.)
What is your confidence in the

supplemental information?

fair

very useful

$-$

generally representative of actual conditions but should not be considered accurate

good confidence in Section III radiographs; low confidence in preservice records

very nelpful

$+$

$-$ 

NIREG/CR-2468

PNL -4026

\section{DISTRIBUTION}

No. of

Copies

OFFSITE

\footnotetext{
A. A. Churm

DOE Patent Division

9800 S. Cass Avenue

Argonne, IL 60439

4DO U.S. Nuclear Regulatory Commission

Division of Technical

Information and

Document Control

7920 Norfolk Avenue

Bethesda, MD 20014

2 DOE Technical Information Center

1 U.S. Nuclear Regulatory Commission

Division of Reactor Safety Research

7920 Norfolk Avenue

Bethesda, MD 20014

R. W. Weeks

Argonne Natjonal Laboratory

Argonne, IL 60439

M. G. Hacker

Babcock \& Wilcox Co.

Nuclear Power Generation Dept.

P.0. Box 239

Lynchburg, VA 24505

W. E. Lawrie

Babcock \& Wilcox Co.

P.0. Box 1260

Lynchburg, VA 24505
}

No. of

Copies

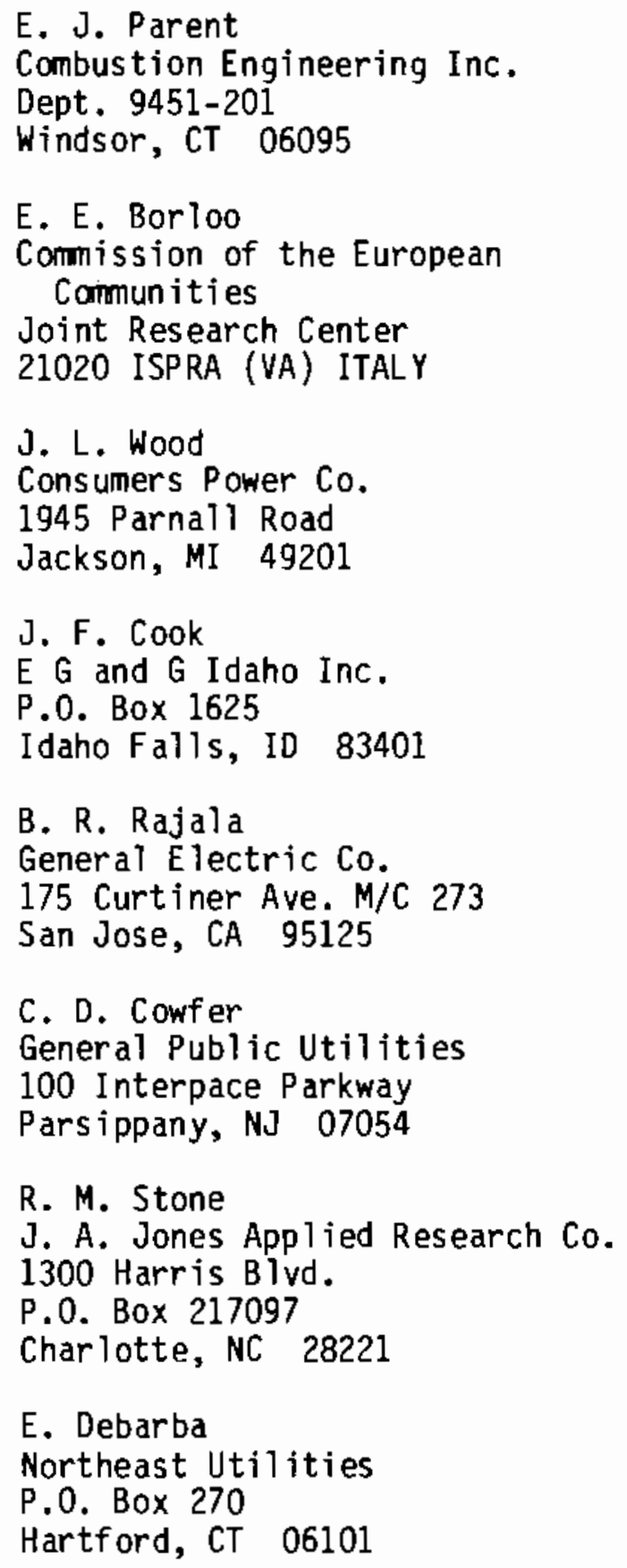

E. J. Parent

Combustion Engineering Inc.

Dept. 9451-201

Windsor, CT 06095

E. E. Borloo

Commission of the European Comunities

Joint Research Center

21020 ISPRA (VA) ITALY

J. L. Wood

Consumers Power Co.

1945 Parnall Road

Jackson, MI 49201

J. F. Cook

$E G$ and $G$ Idaho Inc.

P.0. Box 1625

Idaho Falls, ID 83401

B. R. Rajala

General Electric Co.

175 Curtiner Ave. M/C 273

San Jose, CA 95125

C. D. Cowfer

General Public Utilities

100 Interpace Parkway

Parsippany, NJ 07054

R. M. Stone

J. A. Jones Applied Research $\mathrm{Co}$.

1300 Harris Blvd.

P.0. Box 217097

Charlotte, NC 28221

E. Debarba

Northeast Utilities

P.0. Box 270

Hartford, CT 06101 
No. of

Copies

L. A. Johnson

Nuclear Energy Services Inc.

NES Div.

Shelter Rock Road

Danburg, CT 06810

F. J. Dodd

Pacific Gas and Electric Co.

77 Beal Street, Room 2411

San Francisco, CA 94106

W. T. Clayton

Southwest Research Inst.

6220 Culebra Road

P.0. Drawer 28510

San Antonio, TX 78284

D. C. Adamonis

Westinghouse Electric Corp.

Nuclear Technology Division

P.0. Box 355

Pittsburgh, PA 15230

J. J. Lance

Yanke Atomic Electric Co.

1671 Worcester Road

Fraringham, MA 01701

P. Causs in

Vincotte

1640 Rhode-Saint-Genese

BELGIUM

0. A. Kupcis

Ontario Hydro

Toronto, Ontario M8Z 5S4

CANADA

J. A. de Raad

Delftweg 144

3046 NC Rotterdam

NETHERLANDS
No. of

Copies

\section{0 . For $1 i$}

Det Norske Veritas

Veritasveien, 1

P.0. $80 \times 300$

N-1322 Hovik

NORWAY

Lars-Ake Kornyik

A B Statens Anlaggningsprovning

Kemistvagen 21, Box 51

S-183 21 TABY

SWEDEN

ACE Sinclair

Research Division

Berkeley Nuclear Laboratories

Berke ley

Gloucestershire, GL 139 PB

U.K.

Don Birchon

Admiralty Materials Laboratory

Holton Heal th Poole

Dorser, ENGLAND

020-122-2711

I. P. Bell

Risley Nuclear Labs

UKAEA

Riseley Warrington

Cheshive

U.K.

M. J. Whittle

NDT Application Centre

C.E.G.B. Scientific Services

$T$ impson Road

Manchester M23 9LL

U.K.

P. Holler

Institut fur Zerstrarangs Frere

Prufverfahren

Univ. Geb. 37

0-6600 Saarbucken

WEST GERMANY 
No. of

Copies

X. Ede iman

Sulzer Brothers Ltd

Dept. 1513, NDT

$\mathrm{CH}-8401$ winterthur

SWITZERLAND

\section{ONSITE}

50 Pacific Northwest Laboratory

F. L. Becker (32)

S. H. Bush

R. A. Clark

S. R. Doctor

G. B. Dudder

P. G. Heasler

P. H. Hutton

C. J. Morris

G. J. Posakony

G. P. Selby

F. A. Simonen

A. M. Sutey

Technical Information (5)

Publishing Coordination SH (2)

Distr-3 



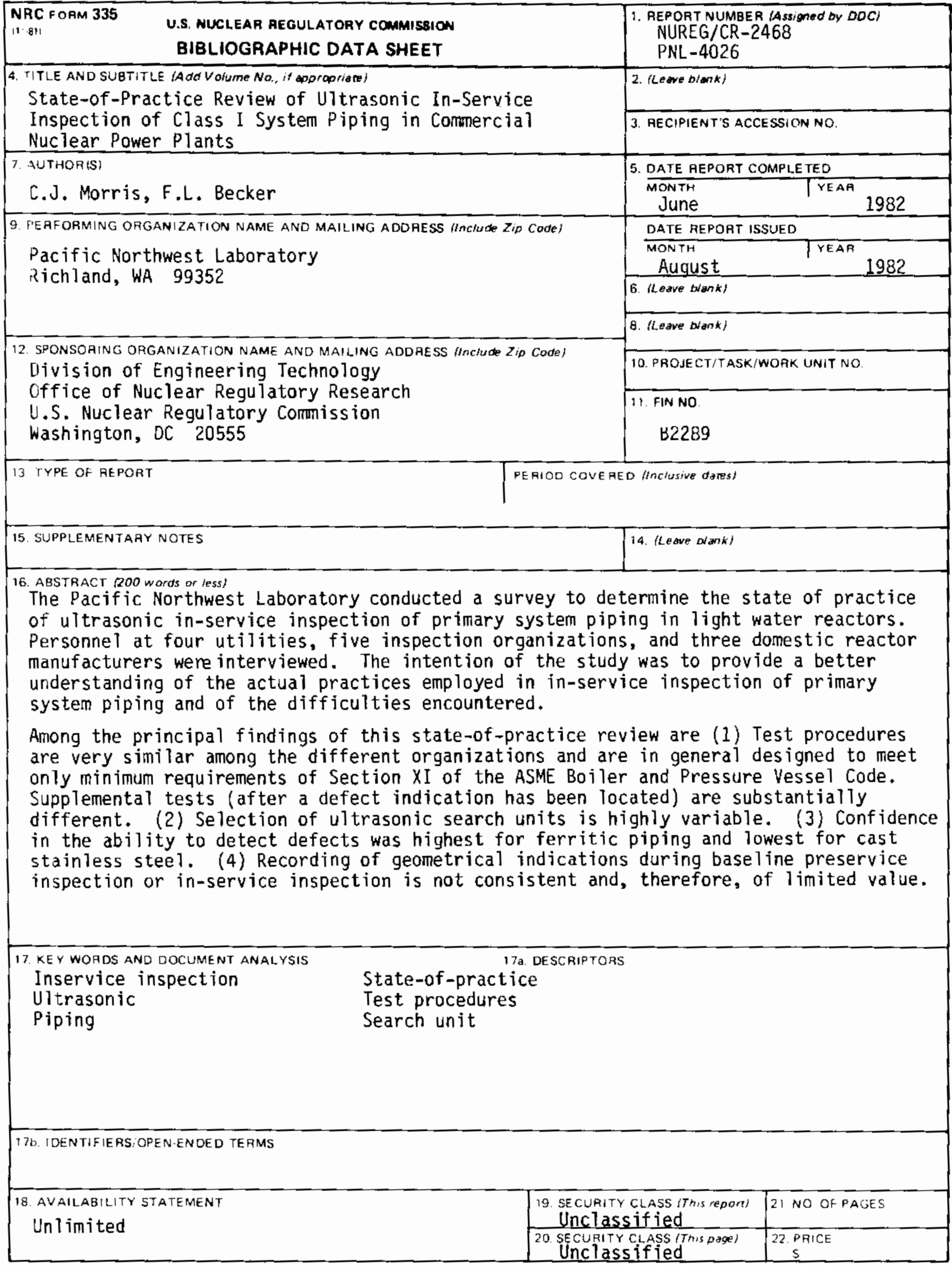


